ORIGINAL ARTICLE

Disinhibition of somatostatin-positive GABAergic interneurons results in an anxiolytic and antidepressant-like

\title{
brain state
}

\author{
T Fuchs $^{1,6}$, SJ Jefferson ${ }^{1,6}$, A Hooper ${ }^{2}$, P-HP Yee ${ }^{1}$, J Maguire ${ }^{3}$ and B Luscher ${ }^{1,4,5}$
}

\begin{abstract}
Major depressive disorder (MDD) is associated with reduced concentrations of $Y$-aminobutyric acid (GABA) that are normalized by antidepressant therapies. Moreover, depressive-like phenotypes of $\mathrm{GABA}_{\mathrm{A}}$ receptor mutant mice can be reversed by treatment with conventional antidepressants drugs, as well as by subanesthetic doses of ketamine. Thus GABAergic deficits may causally contribute to depressive disorders, while antidepressant therapies may enhance GABAergic synaptic transmission. Here we tested the hypothesis that sustained enhancement of GABAergic transmission alone is sufficient to elicit antidepressant-like behavior, using disinhibition of GABAergic interneurons. We focused on somatostatin-positive $\left(\mathrm{SST}^{+}\right) \mathrm{GABAergic}$ interneurons because of evidence that their function is compromised in MDD. To disinhibit SST interneurons, we inactivated the $\gamma 2$ subunit gene of GABA receptors selectively in these neurons (SSTCre: $\gamma 2^{\mathrm{f} / \mathrm{f}}$ mice). Loss of inhibitory synaptic input resulted in increased excitability of SST ${ }^{+}$ interneurons. In turn, pyramidal cell targets of $\mathrm{SST}^{+}$neurons showed an increased frequency of spontaneous inhibitory postsynaptic currents. The behavior of SSTCre: $\gamma 2^{\mathrm{f} / \mathrm{f}}$ mice mimicked the effects of anxiolytic and antidepressant drugs in a number of behavioral tests, without affecting performance in a spatial learning- and memory-dependent task. Finally, brain extracts of SSTCre: $2^{\mathrm{f} / \mathrm{f}}$ mice showed decreased phosphorylation of the eukaryotic elongation factor eEF2, reminiscent of the effects of ketamine. Importantly, these effects occurred without altered activity of the mammalian target of rapamycin pathway nor did they involve altered expression of SST. However, they were associated with reduced $\mathrm{Ca}^{2+} /$ calmodulin-dependent auto-phosphorylation of eEF2 kinase, which controls the activity of eEF2 as its single target. Thus enhancing GABAergic inhibitory synaptic inputs from SST ${ }^{+}$interneurons to pyramidal cells and corresponding chronic reductions in the synaptic excitation:inhibition ratio represents a novel strategy for antidepressant therapies that reproduces behavioral and biochemical end points of rapidly acting antidepressants.
\end{abstract}

Molecular Psychiatry (2017) 22, 920-930; doi:10.1038/mp.2016.188; published online 8 November 2016

\section{INTRODUCTION}

Major depressive disorder (MDD) is a highly disabling and phenotypically heterogeneous psychiatric syndrome that affects up to $17 \%$ of the worldwide population at least once in their lives. ${ }^{1}$ The biology underlying depressive brain states remains poorly understood. However, studies of patients and animal models increasingly suggest a key role for functional imbalances between the major excitatory and inhibitory neurotransmitters, glutamate and $\gamma$-aminobutyric acid (GABA) and their respective receptors. Evidence from analyses of depressed patients includes reduced expression of plasma membrane glutamate transporters ${ }^{2,3}$ and elevated brain concentrations of glutamate. ${ }^{4}$ Conversely, MDD is also associated with reduced concentrations of $G A B A,{ }^{5-10}$ reduced expression of GABA type $A$ receptors $\left(G A B A_{A} R s\right){ }_{1}^{11}$ reduced expression of glutamic acid decarboxylase ${ }^{12,13}$ and impaired function of certain subtypes of GABAergic interneurons. ${ }^{14-16}$ Glutamic acid decarboxylase functions as a key enzyme in the synthesis of GABA from glutamate; its reduced expression therefore could account for both the reduced concentrations of GABA and elevated glutamate. Such neurochemically based excitation-inhibition (E:I) imbalances may directly cause MDD, or they may increase the vulnerability to environmental factors that precipitate depressive episodes, such as uncontrollable stress.

Studies in rodents indicate that chronic and excessive stress can lead to impaired inhibition of neural circuits by a shift in the chloride reversal potential $\left(E_{C I}\right)$ of neurons, which renders GABA ineffective as an inhibitory neurotransmitter, as shown for principal neurons of the paraventricular nucleus of the hypothalamus that control the stress axis, as well as the hippocampus. ${ }^{17-19}$ Intriguingly, the cellular vulnerability to stress is exacerbated in a major subclass of GABAergic interneurons that express the neuropeptide somatostatin (SST, also known as SOM or SRIF) ${ }^{20}$ (see also below). Thus E:I imbalances and uncontrollable stress are subject to reciprocal positive reinforcement and have been implicated independently as causal factors for MDD (for reviews, see Maguire, ${ }^{21}$ Luscher and Fuchs ${ }^{22}$ and Bains et al. ${ }^{23}$ ).

The vast majority of currently used antidepressants are designed to modulate monoaminergic neurotransmitter systems. Their therapeutic effectiveness is delayed by several weeks, indicating that the drug-induced changes that ameliorate

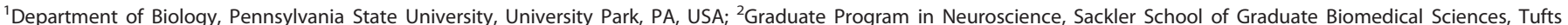

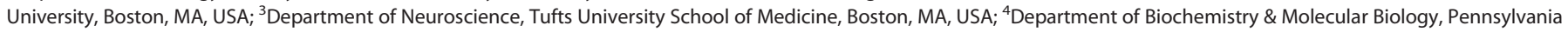

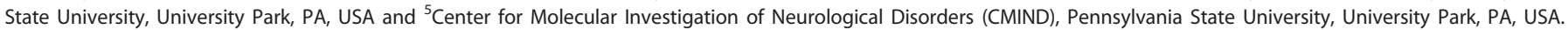
Correspondence: Professor B Luscher, Department of Biology, Pennsylania State University, 301 Life Sciences Building, University Park, PA 16802, USA.

E-mail: BXL25@psu.edu

${ }^{6}$ These authors contributed equally to this work.

Received 4 May 2016; revised 14 August 2016; accepted 31 August 2016; published online 8 November 2016 
depressive brain states are only remotely related to changes in the function of monoamine transmitters. Instead these antidepressants ultimately may affect the functional balance of the major amino-acid neurotransmitters glutamate and GABA. ${ }^{22}$ Indeed, successful antidepressant drug treatment and electroconvulsive therapy of patients are associated with a normalization of GABA concentrations in the brain. ${ }^{24-26}$ Moreover, anxious-depressive-like phenotypes of mice induced by globally reduced function of $\mathrm{GABA}_{\mathrm{A}} \mathrm{Rs}\left(\mathrm{GABA}_{\mathrm{A}} \mathrm{R} \mathrm{Y2}^{+/-}\right.$mice) are normalized by chronic treatment with antidepressant drugs, such as the tricyclic desipramine. ${ }^{27}$ Similar to the delayed effects of conventional antidepressants, the rapidly acting experimental antidepressant, ketamine, normalizes the depressive-like phenotypes of $G A B A_{A} R$ $\mathrm{Y}^{+/-}$mice, along with prominent potentiation of inhibitory synapses in the medial prefrontal cortex (mPFC). ${ }^{28}$ Collectively, these observations indicate that antidepressant therapies act by normalizing chronic E:I imbalances, perhaps through potentiation of GABAergic synaptic inhibition. However, none of these data demonstrate a causative relationship between enhanced GABAergic synaptic transmission and effective antidepressant therapies.

Ketamine's remarkable efficacy as a rapidly acting antidepressant has spurred interest into understanding the underlying mechanism. Ketamine acts by promoting the formation and function of synapses ${ }^{28,29}$ by triggering a cascade of phosphorylation events involving activation of mammalian target of rapamycin (mTOR), ${ }^{29}$ activation of its target p70S6K (S6K), inhibition of the eukaryotic translational elongation factor 2 kinase $(e E F 2 K)$ and reduced inhibitory phosphorylation of the single eEF2K target, eEF2, which ultimately leads to enhanced activity of eEF2 and increased mRNA translation elongation ${ }^{30}$ (reviewed in Duman et al. $^{31}$; however, see also Zanos et al. $^{32}$ ). Notably, mTOR and eEF2 are also activated downstream of antagonists of the $5-\mathrm{HT} 2 \mathrm{C}$ receptor, which have antidepressant-like effects in rodents that are more rapid in onset than currently used antidepressants but slower than ketamine. ${ }^{33}$ A separate line of research employing pharmacological manipulation of neurons in culture has identified $\mathrm{Ca}^{2+} /$ calmodulin (CaM)-dependent auto-phosphorylation of eEF2K and eEF2K-mediated phosphorylation of eEF2 as a sensor mechanism that couples altered synaptic activity to intracellular $\mathrm{Ca}^{2+}$ signaling and increased dendritic mRNA translation elongation. ${ }^{34,35}$ Moreover, the antidepressant response to ketamine is drastically enhanced by defects in GABAergic synaptic transmission. ${ }^{28}$ Thus altered dendritic translation provides a possible link between changes in synaptic activity and altered depression-related brain states. ${ }^{36}$

SST-positive $\left(\mathrm{SST}^{+}\right)$GABAergic interneurons are implicated in MDD owing to reduced expression of SST in the postmortem brain of patients ${ }^{13,14,37,38}$ as well as in stress-based mouse models of depression. ${ }^{20}$ In the neocortex, $\mathrm{SST}^{+}$neurons comprise about $30 \%$ of all interneurons, and they consist mostly of dendrite-targeting Martinotti cells. ${ }^{39}$ They provide feed forward inhibition in proportion with network activity by limiting $N$-methyl-D-aspartate (NMDA) receptor-mediated $\mathrm{Ca}^{2+}$ entry into dendritic spines of principal cells. ${ }^{40-43}$ In the hippocampus, $\mathrm{SST}^{+}$interneurons that function analogously to Martinotti cells reside in the $S$. oriens of the $\mathrm{CA} 1$ region and project to distal apical dendrites of pyramidal cells in the S. lacunosum moleculare. These O-LM cells are tailored to gate glutamatergic inputs from the entorhinal cortex to CA1 pyramidal cells, ${ }^{44,45}$ a type of synapse that is uniquely sensitive to defects in GABAergic inhibition and stress. ${ }^{28,46}$ The activity of Martinotti and O-LM cells and other SST ${ }^{+}$hippocampal interneurons (bistratified interneurons) scales with network activity specifically in the theta frequency, ${ }^{47-50}$ a network property that is also enhanced by anxiolytic and antidepressant drugs. ${ }^{51}$ It is conceivable, therefore, that the therapeutic effects of antidepressants involve increased GABAergic synaptic inhibition by $\mathrm{SST}^{+}$ interneurons in both the neocortex and hippocampus.
Here we used a molecular genetic approach to directly examine whether enhancement of GABAergic synaptic transmission through disinhibition of $\mathrm{SST}^{+}$GABAergic interneurons can cause antidepressant-like behavior. The $\gamma 2$ subunit of $G A B A_{A} R s$ is essential for synaptic localization of $G_{A B A} R s$ and for GABAergic synaptic inhibition of all neurons. ${ }^{52-55}$ Therefore, to disinhibit SST ${ }^{+}$ neurons we chose to delete $\gamma 2$ selectively in forebrain $\mathrm{SST}^{+}$ neurons, using Cre-mediated inactivation of a 'floxed' $\gamma 2$ allele. ${ }^{53}$ As predicted, SSTCre: $2^{\mathrm{f} / \mathrm{f}}$ mice showed increased excitability of $\mathrm{SST}^{+}$neurons that resulted in enhanced inhibitory synaptic inputs to pyramidal cells in CA1 of the hippocampus and layers 2/3 (L2/3) of the cingulate cortex. Behaviorally, SSTCre: $\mathrm{Y}^{\mathrm{f} / \mathrm{f}}$ mice showed a robust anxiolytic- and antidepressive-like phenotype. Moreover, brain extracts of SSTCre: $2^{\mathrm{f} / \mathrm{f}}$ mice showed reduced phosphorylation of the eukaryotic elongation factor eEF2. Importantly, these changes did not involve altered mTOR activity nor altered expression of SST but they were correlated with reduced CaMdependent activating auto-phosphorylation of eEF2K and reduced inhibitory phosphorylation of its single target, eEF2. Thus reducing the E:I ratio of principal neurons through chronic enhancement of GABAergic synaptic inhibition reproduces the behavioral and molecular end points of rapidly acting antidepressant drugs ${ }^{30,33}$ through a reduction in intracellular $\mathrm{Ca}^{2+}$ signaling and independent of mTOR activation, thereby providing a novel mechanistic concept for development of antidepressant therapies.

\section{MATERIALS AND METHODS}

A more detailed description is found in Supplementary Information.

Animals

All animal experiments were approved by the Institutional Animal Care and Use Committees (IACUC) of The Pennsylvania State University or Tufts University and performed in accordance with all relevant guidelines and regulations of the National Institute of Health (NIH). SSTCre mice were obtained from JAX mice (Stock no. 013044, Jackson Laboratory, Bar Harbor, ME, USA). The $\mathrm{Y2}^{\mathrm{f} / \mathrm{f}}$ mice were generated in house. ${ }^{53}$ The LSL-YFP Crereporter strain also known as ROSA26-EYFP ${ }^{56}$ was obtained from JAX mice (Stock no. 006148). All mice were backcrossed to the $129 \times 1 /$ SvJ genetic background for at least six generations. The genotypes compared were produced as littermates and identified by PCR analyses of tail DNA as described. ${ }^{57}$ The mice were maintained on a 12:12 $\mathrm{h}$ light-dark cycle with food and water available ad libitum.

\section{Immunohistochemistry}

Mice were anesthetized with Avertin and perfused with ice-cold artificial cerebrospinal fluid. Brain halves were subjected to emersion fixation in $4 \%$ paraformaldehyde in phosphate-buffered saline for $60 \mathrm{~min}$ and cryoprotected in 30\% sucrose overnight. Floating sections $(30 \mu \mathrm{m})$ were immunostained using chicken anti-green fluorescent protein (1:1000, no. GFP-1020, Aves Labs, Tigard, OR, USA), guinea pig anti-GABA ${ }_{A} R$ Y2 (1:500, no. 224 004, Synaptic Systems, Göttingen, Germany) and mAb7a anti-gephyrin (1:500, no. 147011, Synaptic Systems) and developed using secondary antibodies raised in goat and conjugated to Alexa 647 (Jackson Immuno Research, West Grove, PA, USA), Alexa 488 or Cy3 (Molecular Probes, Eugene, OR, USA). Confocal image stacks of $\mathrm{YFP}^{+}$neural somata were captured using an Olympus FV-1000 microscope with a $\times 100 / N A 1.4$ oil objective (HUNT OPTICS \& IMAGING, Pittsburgh, PA, USA), collapsed and quantitated using Image J (https://imagej.nih.gov/ij/). Measures of the YFP ${ }^{+}$area of somata and number of puncta were used to determine puncta densities.

Electrophysiological recordings

Electrophysiological recordings were carried out essentially as described. ${ }^{58}$

\section{Behavioral testing}

Behavioral testing started at 9 weeks of age, with one test per week and starting with the open field test (OFT), followed by elevated plus maze (EPM), novelty suppressed feeding test (NSFT) and forced swimming test (FST). The learned helplessness test (LHT) was conducted with a separate 
cohort of mice. All testing was performed under red light, between 2 and $6 \mathrm{~h}$ after the beginning of the dark phase and scored by investigators blind to genotype. The OFT was used to assess locomotion in a novel environment, under red light. The behavior was video recorded and motor activity (path length) was analyzed in 5 min bins using the EthoVision XT video tracking system (Noldus Information Technologies, Leesburg, VA, USA). For the $\mathrm{EPM}^{59}$ mice were placed into the center square of the maze facing a closed arm. Behavior was video recorded for 5 min using EthoVision XT. For the NSFT, ${ }^{60}$ mice were food deprived for $18 \mathrm{~h}$. The latency to feed in a novel arena was hand scored. In the FST, ${ }^{61}$ we assessed the average swim speed during the first minute, the latency to the first episode of passive floating (time to first immobility) and the total time immobile during the last $4 \mathrm{~min}$ of a $6 \mathrm{~min}$ test, using Ethovision XT. The LHT was modified from reference. ${ }^{62}$ Mice were exposed to 120 inescapable foot shocks $(0.3 \mathrm{~mA}, 15 \mathrm{~s})$ at an average interval of $45 \mathrm{~s}$ in a two-compartment shuttle box with the connecting gate closed (SanDiego Instruments, San Diego, CA, USA). Twenty-four hours later, mice were tested in the same shuttle box in a 30-trial active avoidance task (escapable foot shock). Escape failures were recorded automatically.

\section{Western blotting}

Tissue extracts in $50 \mathrm{~mm}$ Tris- $\mathrm{HCl}(\mathrm{pH} 8.0), 150 \mathrm{~mm} \mathrm{NaCl}, 2 \mathrm{~mm}$ EDTA, $0.1 \%$ sodium dodecyl sulfate, $1 \%$ Triton X-100, $1 \mathrm{~mm} \mathrm{NaVO}, 5 \mathrm{~mm} \mathrm{NaF}$ and $1 \times$ protease inhibitor cocktail (Roche, Basel, Switzerland) were analyzed by 4-12\% sodium dodecyl sulfate-polyacrylamide gel electrophoresis, transferred to polyvinylidene difluoride membranes and probed with mouse anti $\beta$-tubulin (1:10 000, no. T8328, Sigma-Aldrich, St Louis, MO, USA), rabbit anti-eEF2K (1:500, no. 4661), rabbit anti-phospho-eEF2K (Thr348) (1:500, no. 4411), rabbit anti-phospho-eEF2K (Ser500) (1:500, no. 4451, all a
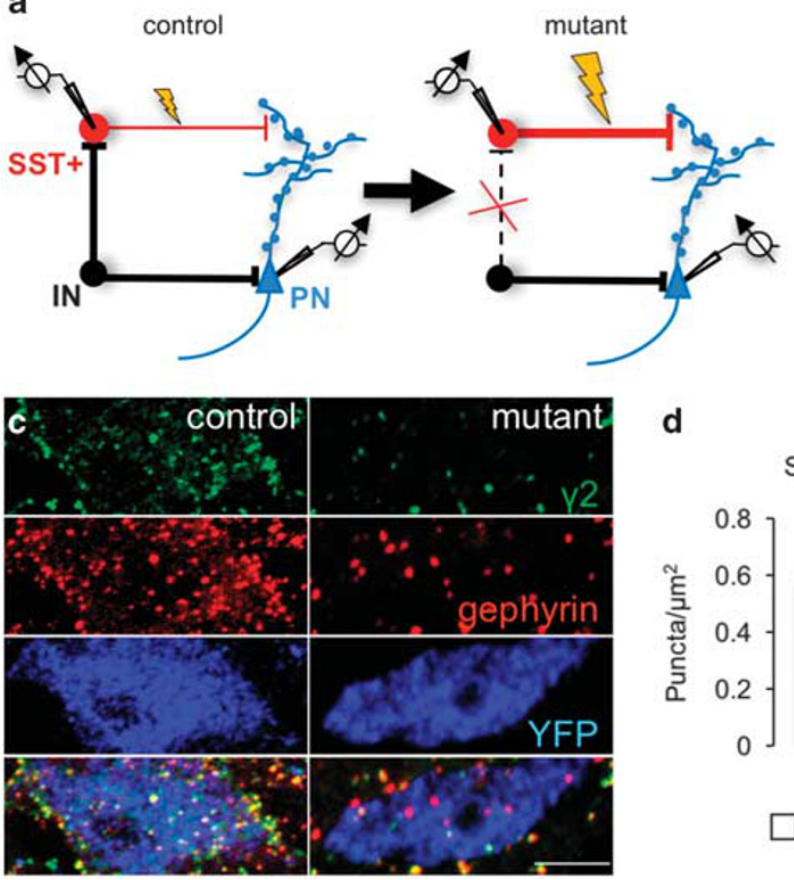

d

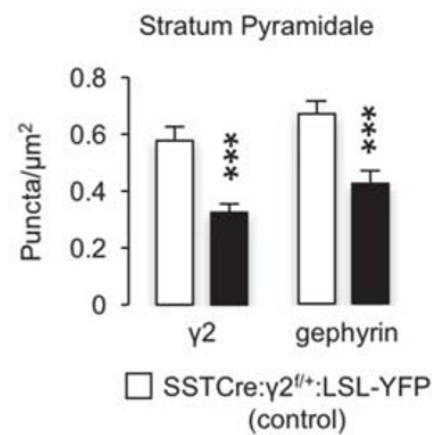

b
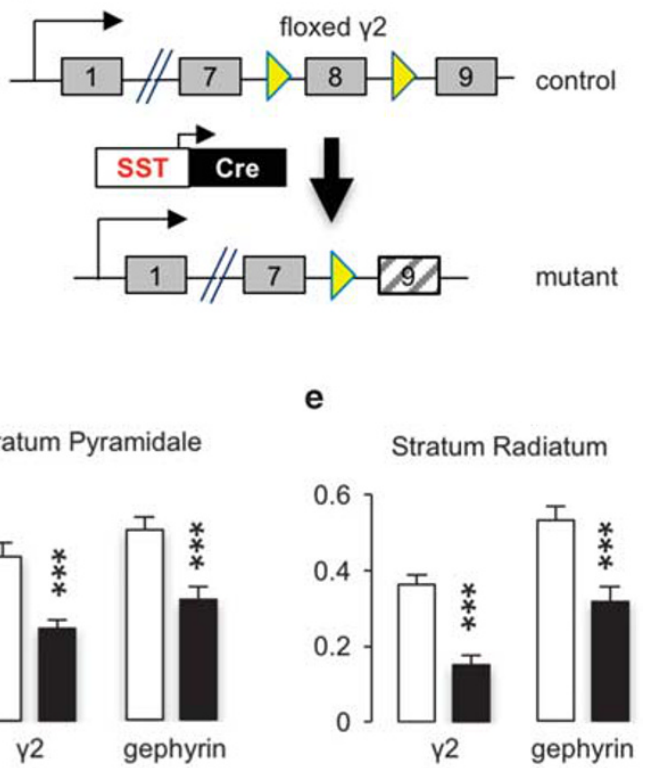

SSTCre:Y2 ${ }^{\text {ff }}:$ LSL-YFP (mutant)

Figure 1. Deletion of postsynaptic $\gamma$-aminobutyric acid type $A$ receptors $\left(G A B A_{A} R s\right)$ and gephyrin from somatostatin-positive $\left(S S T^{+}\right)$neurons of SSTCre: $\gamma 2^{\mathrm{f} / \mathrm{f}}$ mice. (a) Strategy for $\gamma 2$ subunit knockout-mediated disinhibition of $\mathrm{SST}^{+}$interneurons. Loss of synaptic GABA $\mathrm{R}_{\mathrm{A}}$ removes inhibitory input (IN) to SST ${ }^{+}$neurons and increases excitability of these neurons. Increased excitability of $\mathrm{SST}^{+}$neurons strengthens inhibitory synaptic inputs to apical dendrites and spines of pyramidal cells (PN). (b) Schematic of Cre-mediated inactivation of the 'floxed' $\gamma 2$ locus. (c) Representative micrographs of the soma of an SST ${ }^{+}$neuron from a SSTCre: $\gamma 2^{f /+}$ :LSL-YFP control mouse (left column) compared with a SST neuron from a SSTCre: $\gamma 2^{f / f}$ :LSL-YFP mutant animal, immunostained for the $\gamma 2$ subunit (top row, green), gephyrin (second row; red) and yellow fluorescent protein (YFP; third row; blue) with merged images showing colocalization of $\gamma 2$ and gephyrin in yellow in the bottom row. Note the drastic reduction in punctate staining for both the $\gamma 2$ subunit and gephyrin, indicative of loss of functional synapses. Residual staining for $\gamma 2$ is likely attributable to dendrites of Cre-lacking neighboring neurons. (d) Quantification of puncta densities overlapping with YFP ${ }^{+}$cell somata (puncta per $\mu \mathrm{m}^{2}$ ) in S. pyramidale and S. radiale of the hippocampus. Densities for both proteins were significantly reduced in both areas $\left(P<0.001\right.$, respectively). ${ }^{* *} P<0.001$, Mann-Whitney, $n=30-40$ cells, 2 mice/genotype.

Figure 2. Recordings from somatostatin-positive $\left(\mathrm{SST}^{+}\right)$neurons. (a-f) Spontaneous inhibitory synaptic current (sIPSC), miniature inhibitory synaptic current (mIPSC) and spontaneous excitatory postsynaptic current (sEPSC) recordings from SST ${ }^{+}$neurons of SSTCre: $\gamma 2^{\mathrm{f} / \mathrm{f}}:$ :LSL-YFP mutants and SSTCre: $\gamma 2^{\mathrm{f} /+}$ :LSL-YFP control mice in hippocampus CA1 (a-c) and L2/3 cingulate cortex (d-f). Representative traces are shown on top of the summary statistics. Note the significant reductions in both sIPSC and mIPSC frequencies and amplitudes recorded from CA1 (a, b) and L2/3 (d, e) SST ${ }^{+}$neurons of mutant vs control mice $(P<0.05$ for all eight measures, $n=6$ and 8 cells, one cell/slice, three mice/genotype). sEPSCs recorded from SST ${ }^{+}$neurons were unaffected by genotype independent of brain area (c, f, CA1, L2/3 frequency, $P$, NS (non-significant); amplitude, $P$, NS; $n=6$ and 8 cells and slices, 3 mice/genotype). (g-n) Current injection data from SST ${ }^{+}$neurons in CA1 and L2/3 cingulate cortex of SSTCre: $\gamma 2^{\mathrm{f} / \mathrm{f}}$ :LSL-YFP mutants and controls. Representative traces are shown in panels (g) (CA1) and (k) (L2/3) with summary data in panels (h-j) (CA1) and (I-n) (L2/3). Note the increased number of action potentials recorded from SST ${ }^{+}$neurons in mutant vs control mice in both CA1 and L2/3 (h, I) $\left(P<0.05\right.$ for both comparisons, Bolzman fit, W50, $t$-tests). The input resistance $\left(R_{\text {ini }} \mathbf{j}\right.$, $\left.\mathbf{n}\right)$ was significantly reduced in SSTCre: $\gamma 2^{\mathrm{f} / \mathrm{f}}:$ LSL-YFP mutant vs control mice in both brain areas $\left(R_{\text {in }}, \mathrm{CA} 1, P<0.05 ; \mathrm{L} 2 / 3, P<0.01, n=9\right.$ and 10$)$, while the resting membrane potentials (RMP; $\mathbf{j}, \mathbf{n})$ of $\mathrm{SST}^{+}$cells were unaffected by genotype independent of brain area (RMP, $\left.P, \mathrm{NS}\right)$. Data represent means \pm s.e. ${ }^{*} P<0.05$, $* * P<0.01, t$-tests. 
from ECM Biosciences, Versailles, KY, USA), rabbit anti-phospho-eEF2 (Thr56) (1:500, no. 2331), rabbit anti-eEF2 (1:500, no. 2332), rabbit antiphosphor-mTOR (Ser2448) (1:500, no. 5536), mouse anti-mTOR (1:500, no. 4517), rabbit anti-phosphor-p70S6K (Thr389) (1:500, no. 9205) and rabbit
anti-p70S6K (1:500, no. 9202) (all from Cell Signaling Technology, Danvers, MA, USA). Immunoreactive bands were developed and quantitated using IRDye secondary antibodies and an Odyssey CLx infrared imager (LI-COR) using conditions recommended by LI-COR (Lincoln, NE, USA). a

sIPSCs

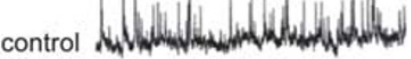

mutant

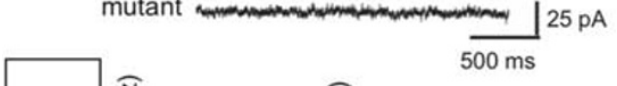

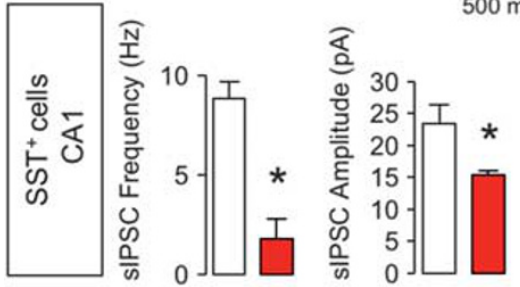

b
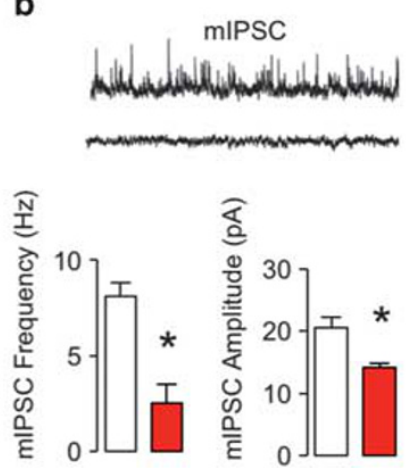

SSTCre:Y2 $2^{f / *}:$ LSL-YFP (control)

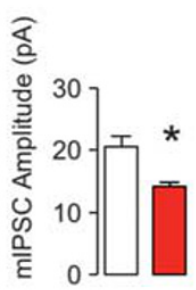

C

SEPSC

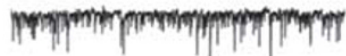

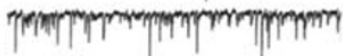
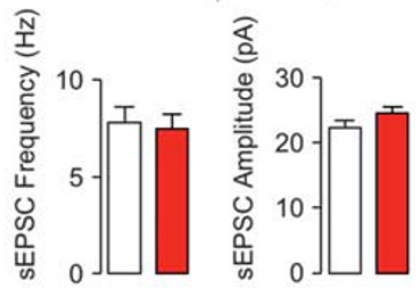

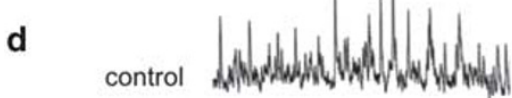

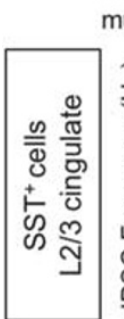
mutant

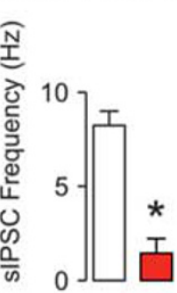

g

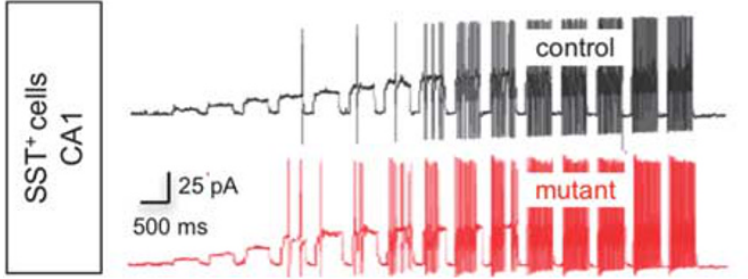

k

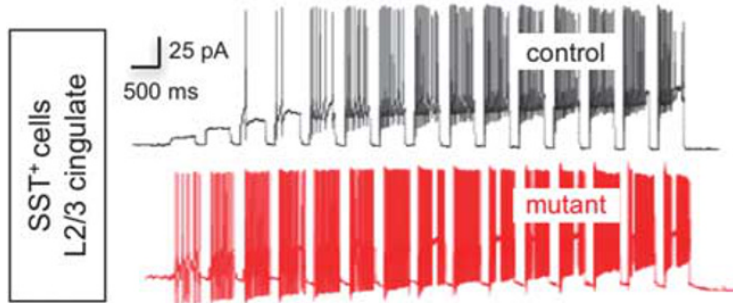

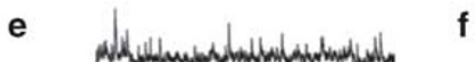

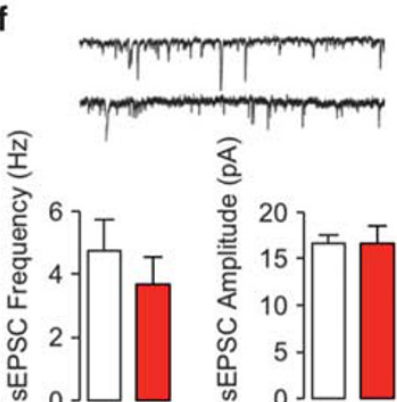

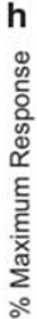

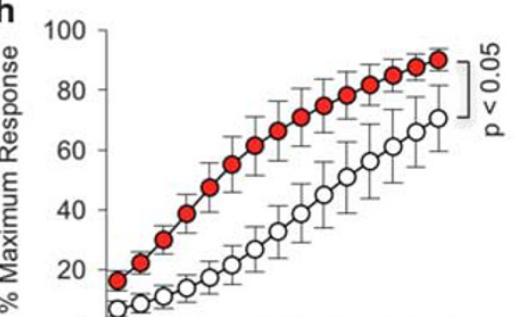

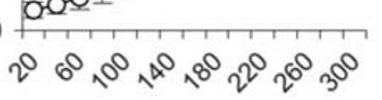

-0- SSTCre:Y2 $2^{\text {fif }}$ LSL-YFP (mutant)

$\multimap$ - SSTCre:Y2 $2^{f / *}:$ LSL-YFP

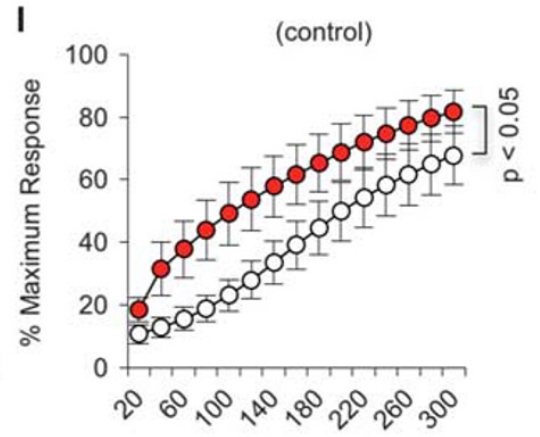

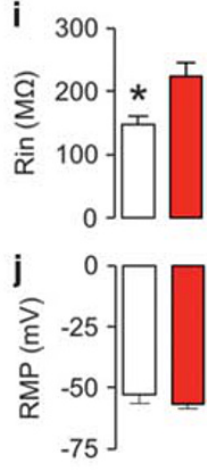

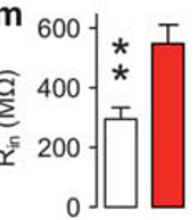

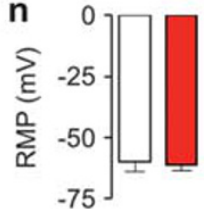


Enzyme-linked immunosorbent assay

Brain tissue was extracted by sonication in $20 \mathrm{~mm}$ Tris- $\mathrm{HCl}, 137 \mathrm{~mm} \mathrm{NaCl}$, $0.2 \%$ Triton X-100, $10 \%$ glycerol and $1 \times$ protease inhibitor cocktail (Roche) and cleared by centrifugation. The SST concentration in supernatants was measured using a Mouse Somatostatin ELISA Kit (F12622, LifeSpan Biosciences, Seattle, WA, USA).

Real-time quantitative PCR

Total RNA was extracted from brain tissue using the GenElute Mammalian Total RNA Miniprep Kit (Sigma-Aldrich). Reverse transcription was performed using the qScript cDNA Supermix (Quanta Biosciences, Gaithersburg, MD, USA). PCR reactions were performed in triplicate and normalized to a $\beta$-actin internal control, using primers designed with the Primer Express software (Thermo Fisher Scientific, Waltham, MA, USA). Quantification was performed using the comparative threshold cycle $\left(C_{t}\right)$ measurement with SYBR green fluorescence signal (Quanta Biosciences).

\section{Statistics}

All statistical analyses were based on biological replicates. Group means that satisfied the normality assumption (D'Agostino and Pearson) were compared by two-tailed unpaired $t$-tests or, in case of multiple group means, by analysis of variance followed by planned comparisons using $t$ tests, as detailed in figure legends (PRISM software, Graphpad, La Jolla, CA, USA). Data subjected to analyses of variance (latency to feed, time to first immobility and eEFK ${ }^{\mathrm{T} 348}$ phosphorylation) were log transformed to satisfy the normality assumption. Two-group comparisons of data for which the normality assumption could not be ascertained were analyzed by MannWhitney $U$-test. Outliers that deviated from the mean by $>2$ s.d. were removed from analyses.

\section{RESULTS}

Deletion of postsynaptic $\mathrm{GABA}_{A} \mathrm{Rs}$ from $\mathrm{SST}^{+}$neurons results in increased excitability of these neurons

To examine whether increasing the excitability of $\mathrm{SST}^{+}$interneurons results in an antidepressant phenotype, we chose to reduce GABAergic inhibitory synaptic input to these neurons (Figure 1a). The $\gamma 2$ subunit of $G_{A B A} R s$ is essential for postsynaptic accumulation of $G A B A_{A} R s$ and the subsynaptic scaffolding protein gephyrin, for normal channel conductance of $G A B A_{A} R s$, and for GABAergic synaptic function. ${ }^{63,52,54}$ To selectively inactivate the $\gamma 2$ gene (Gabrg2) in $\mathrm{SST}^{+}$interneurons we crossed mice carrying the Cre-driver SSTCre ${ }^{64}$ and the Cre-reporter LSL-YFP with 'floxed' $\gamma 2$ mice $\left(\gamma 2^{\mathrm{f} / \mathrm{f}} \text { mice }\right)^{53}$ (Figure $\left.1 \mathrm{~b}\right)$. As expected, the punctate immunoreactivity for $\mathrm{GABA}_{\mathrm{A}}$ Rs that overlapped with $\mathrm{YFP}^{+}$somata of $\mathrm{SST}^{+}$neurons was drastically reduced in SSTCre: $Y 2^{\mathrm{f} / \mathrm{f}}: \mathrm{LSL}-\mathrm{YFP}$ mice compared with SSTCre:Y $2^{f /+}:$ LSL-YFP (heterozygous) controls, as demonstrated for S. pyramidale and S. radiatum (Figures 1c-e). The punctate immunoreactivity for gephyrin was similarly reduced, consistent with the loss of postsynaptic $G_{A B A} R s$ (Figures $1 \mathrm{c}-\mathrm{e}$ ). Punctate immunoreactivity remaining for $\mathrm{\gamma} 2$ was likely due to dendrites of Cre-lacking neighboring neurons that invaded the optic plane imaged of $\mathrm{YFP}^{+}$somata, indicating that the loss of inhibitory synapses may be more drastic than these data suggest.

We next performed V-clamp recordings from $\mathrm{SST}^{+}\left(\mathrm{YFP}^{+}\right)$ neurons to assess predicted changes in inhibitory synaptic currents. Recordings from $\mathrm{SST}^{+}$neurons of the $\mathrm{CA} 1$ region of
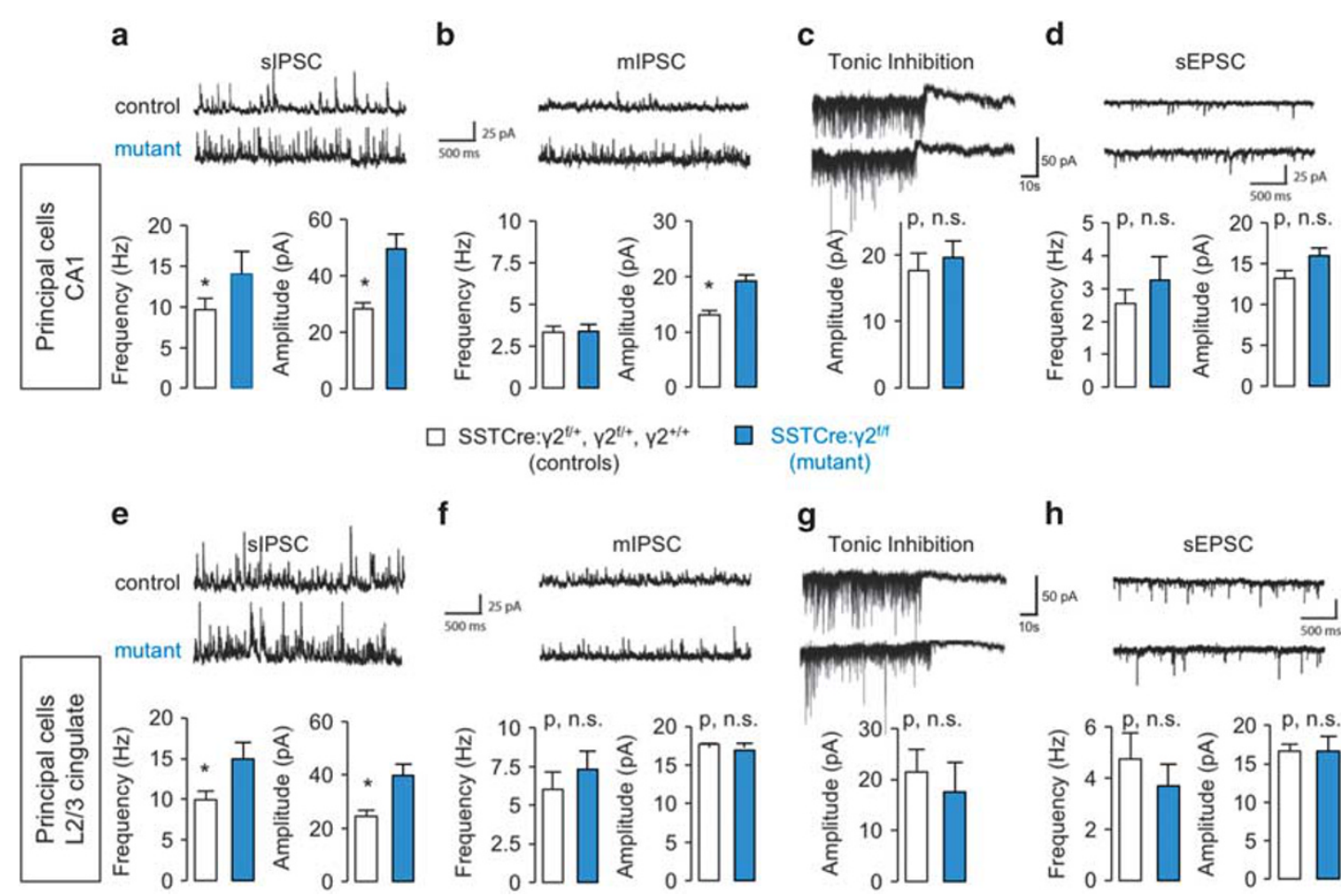

f
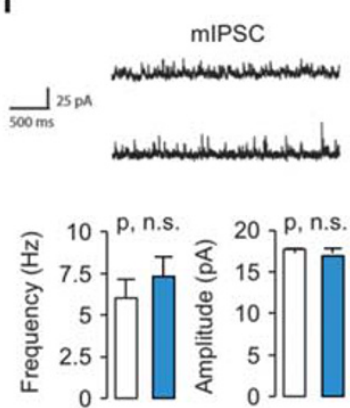

g

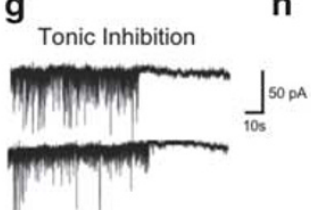

h
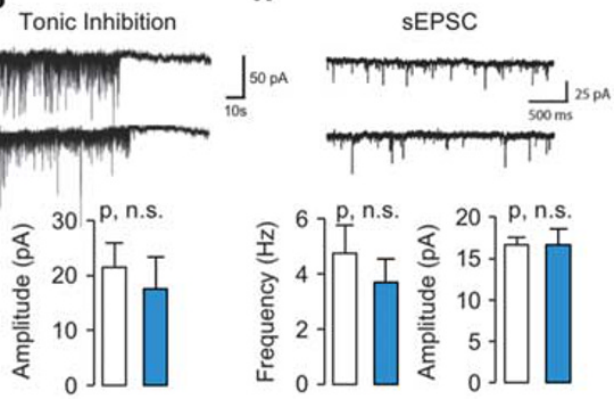

Figure 3. Recordings from pyramidal cells. (a-h) Spontaneous inhibitory synaptic current (sIPSC), miniature inhibitory synaptic current (mIPSC), tonic inhibition and spontaneous excitatory postsynaptic current (sEPSC) recordings from pyramidal neurons of SSTCre: $\gamma 2^{\mathrm{f} / \mathrm{f}}$ compared with control mice (SSTCre: $\gamma 2^{f /+}, \gamma 2^{f / f}$ and $\gamma 2^{+/+}$) in CA1 hippocampus (a-d) and L2/3 cingulate cortex (e-h). Representative traces are shown on top of the bar graph summary statistics. Note the significant increases in SIPSC frequency and amplitude recorded from neurons of SSTCre: $\gamma 2^{\mathrm{f} / \mathrm{f}}$ mice in both brain areas (a, e, $P<0.05$ for all four measures; $n=8$ and 15 neurons, recording 1 neuron/slice, from 4 mice/ genotype). By contrast, mIPSCs showed a moderate increase in amplitude for SSTCre: $\gamma 2^{\mathrm{f} / \mathrm{f}}$ mice in CA1 only (b, f) (CA1 amplitude, $P<0.05$, frequency, $P$, NS (non-significant); for CA1 frequency, L2/3 amplitude and L2/3 frequency). Tonic inhibition (c, g) was unaffected by genotype ( $P$, NS; for all comparisons, $n=8$ and 11 neurons and slices, 3 mice/genotype). Similarly, the sEPSCs (d, h) did not differ between genotypes independent of brain area ( $P$, NS; all comparisons, $n=8$ and 15 neurons and slices, 4 mice/genotype). Data represent means \pm s.e. ${ }^{*} P<0.05$, $t$-tests. 
a

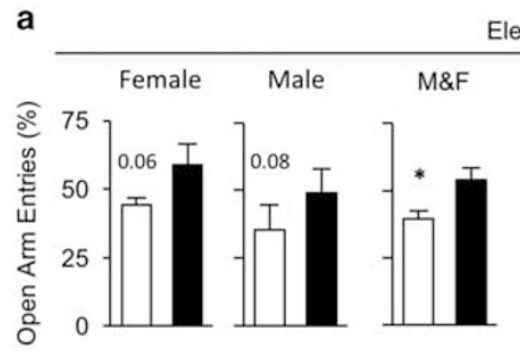

Elevated Plus Maze

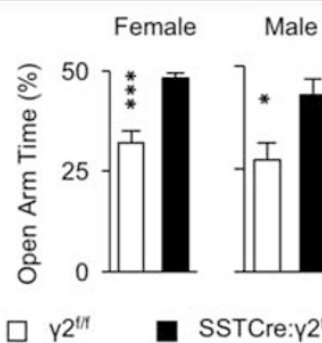

b Novelty Suppressed Feeding

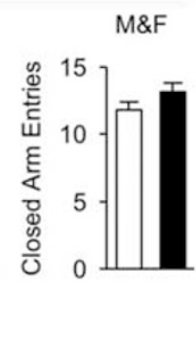

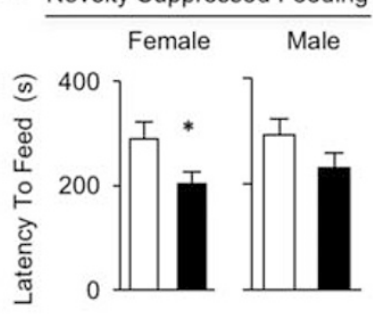

d

Learned Helplessness
C

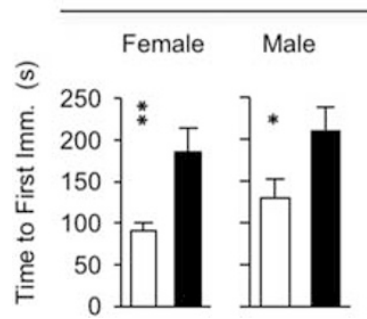

Forced Swim Test

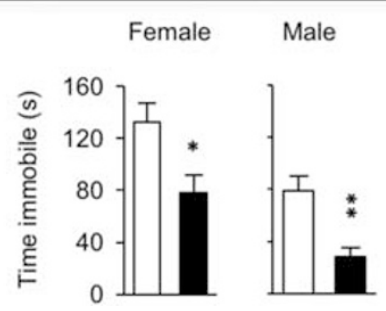

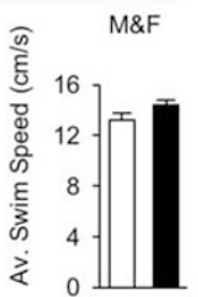

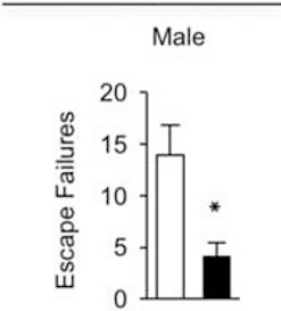

Figure 4. SSTCre: $\gamma 2^{\mathrm{f} / \mathrm{f}}$ mice show an anxiolytic- and antidepressant-like behavioral phenotype. (a) Elevated Plus Maze: Percentage of open arm entries of SSTCre: $\gamma 2^{\mathrm{f} / \mathrm{f}}$ mutants was increased compared with $\gamma 2^{\mathrm{f} / \mathrm{f}}$ controls (sexes combined $(\mathrm{M} \& \mathrm{~F}), \mathrm{F}_{(1,60)}=6.34, P<0.05, n=29$ and 35$)$ with similar trends in females $(P=0.06, n=14$ and 16) and males $(P=0.08, n=15$ and 19). The percentage of time spent in open arms was increased in mutants vs controls in both sexes $\left(\mathrm{F}_{(1,57)}=19.16, P<0.001\right.$; male: $P<0.05, n=14$ and 19; female: $P<0.001, n=16$ and 12). The number of closed arm entries did not differ between genotypes ( $P>0.05$, NS (non-significant), $t$-test). (b) Novelty Suppressed Feeding Test: SSTCre: $2^{\mathrm{f} / \mathrm{f}}$ mutants showed a reduced latency to feed vs controls $\left(\mathrm{F}_{(1,62)}=6.4, P=0.014\right)$, with significant effects in females $(P<0.05, n=16)$ and a tendency in the same direction in males $\left(P, N S ; n=15\right.$ and 19). (c) Forced Swim Test: SSTCre: $\gamma 2^{\mathrm{f} / \mathrm{f}}$ mice of both sexes showed increased latencies to their first bout of immobility $\left(\mathrm{F}_{(1,62)}=15.41, P=0.0002\right.$; female: $P<0.01, n=16$; male: $P<0.05, n=15$ and 19$)$ and a reduced total time immobile vs controls $\left(\mathrm{F}_{(1,62)}=15.98, P<0.0001\right.$; female: $P<0.05$; male: $\left.P<0.01\right)$. The average swim speed during the first minute did not differ between genotypes (M\&F: $P$, NS; $n=32$ and 34, $t$-test). (d) Learned Helplessness Test: Male SSTCre: $\gamma 2^{\mathrm{f} / \mathrm{f}}$ mice showed fewer escape failures than controls $\left(P<0.05, n=17\right.$ and 19 , Mann-Whitney). Data represent means \pm s.e. ${ }^{*} P<0.05$, ${ }^{* *} P<0.01,{ }^{* * *} P<0.001$, analyses of variance and posthoc $t$-tests, $t$-tests or Mann-Whitney.

the hippocampus revealed drastic reductions in the frequencies and amplitudes of both spontaneous and miniature inhibitory synaptic currents (sIPSCs and mIPSCs, respectively) (Figures $2 \mathrm{a}$ and $\mathrm{b}$ ) in SSTCre: $\mathrm{2}^{\mathrm{f} / \mathrm{f}}$ :LSL-YFP mice, consistent with the loss of postsynaptic $G_{A B A} R$ s. Virtually identical results were obtained for $\mathrm{SST}^{+}$neurons of $\mathrm{L} 2 / 3$ cingulate cortex (Figures $2 \mathrm{~d}$ and e). By contrast, spontaneous and miniature excitatory postsynaptic currents (EPSCs) remained unaffected, independent of brain region (Figures $2 c$ and $f$, Supplementary Figures S1A and B).

To assess the changes in excitability of $\mathrm{SST}^{+}$neurons, we performed current clamp recordings in response to a series of current injections, with amplitudes ranging from 20 to 300 pA. The number of action potentials recorded from $\mathrm{SST}^{+}$neurons was significantly increased in SSTCre: $Y 2^{\mathrm{f} / \mathrm{f}}:$ LSL-YFP mutants vS SSTCre: $\mathrm{Y}^{\mathrm{f} / \mathrm{+}}$ :LSL-YFP controls both in CA1 hippocampus (Figures $2 \mathrm{~g}$ and $\mathrm{h}$ ) and $\mathrm{L} 2 / 3$ cingulate cortex (Figures $2 \mathrm{k}$ and $\mathrm{I})(P<0.05$, both comparisons). The input resistance of $\mathrm{SST}^{+}$neurons was increased in mutant vs control mice, independent of brain region and consistent with the reduced number of chloride channels expressed by these cells (Figures $2 \mathrm{i}$ and $\mathrm{m}$ ). By contrast, the resting membrane potential was unaffected, indicating that increased excitability did not adversely affect the energy balance of mutant $\mathrm{SST}^{+}$neurons (Figures $2 \mathrm{j}$ and $\mathrm{n}$ ).

To assess possible secondary changes induced by chronic loss of GABAergic inhibition, we compared the effects of genetic deletion of $G A B A_{A} R s$ with those of pharmacological blockade of $\mathrm{GABA}_{\mathrm{A}} \mathrm{Rs}$. Treatment of slices with bicucullin $(25 \mu \mathrm{M})$ increased the number of current-induced action potentials in control mice to levels recorded from untreated CA1 SST ${ }^{+}$cells of SSTCre:Y2 ${ }^{\mathrm{f} / \mathrm{f}}: \mathrm{LSL}$ -
YFP mutant mice (Supplementary Figures S1C and D, $P, N S$; Bolzman fit, W50, $t$-test). Moreover, the bicucullin effect on the maximum number of action potentials was occluded in the mutants (Supplementary Figures S1C and D). Similarly, the input resistance of $\mathrm{SST}^{+}$neurons recorded from control mice was increased by bicucullin to the levels of mutant mice, without additional drug effect in the mutants (Supplementary Figure S1E). Thus the effect of pharmacological blockade of $G_{A B A} R s$ on excitability of $\mathrm{SST}^{+}$neurons was indistinguishable from that of genetic inactivation of $G A B A_{A} R s$, and there is no evidence for secondary changes that contributed to increased excitability of mutant $\mathrm{SST}^{+}$neurons.

Increased excitability of $\mathrm{SST}^{+}$neurons results in increased GABAergic synaptic inhibition of principal cells

To assess functional consequences of $\mathrm{SST}^{+}$cell hyperexcitability on putative target cells, we performed V-clamp recordings of pyramidal cells. The frequency and amplitude of sIPSCs recorded from pyramidal cells in CA1 was significantly increased in SSTCre: $\mathrm{\gamma}^{\mathrm{f} / \mathrm{f}}$ mice vs controls (SSTCre: $\mathrm{\gamma} 2^{\mathrm{f} /+}, \mathrm{\gamma} 2^{\mathrm{f} /+}$ and $\mathrm{\gamma} 2^{+/+}$) (Figure 3a). By contrast, the frequency of mIPSCs remained unaffected (Figure 3b), consistent with frequency changes being presynaptic action potential dependent. Nevertheless, the mIPSC amplitude was elevated (Figure 3b), indicating that GABAergic synapses of CA1 pyramidal cells were potentiated both presynaptically and postsynaptically. Strengthening of the postsynaptic apparatus is consistent with recent evidence for presynaptic activitydependent plasticity of inhibitory synapses (see Discussion). Tonic $G A B A_{A} R$ currents remained unaffected by genotype (Figure $3 c$ ), in keeping with the absence of spontaneous activity of $\mathrm{SST}^{+}$neurons 


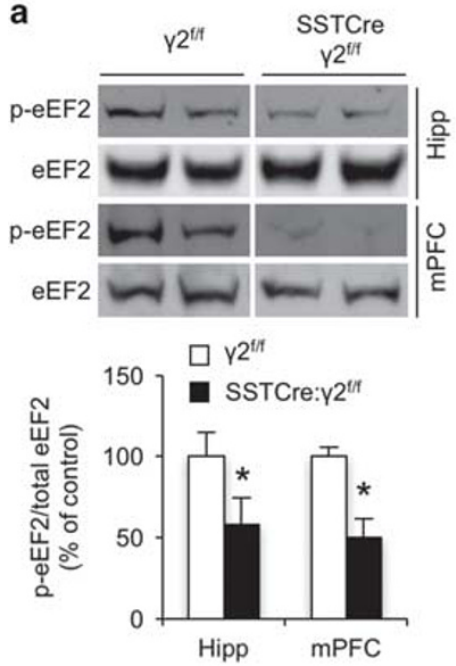

d

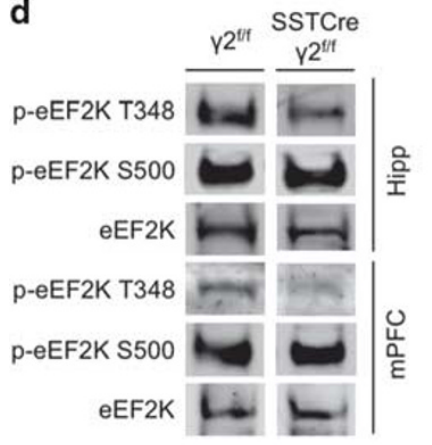

e

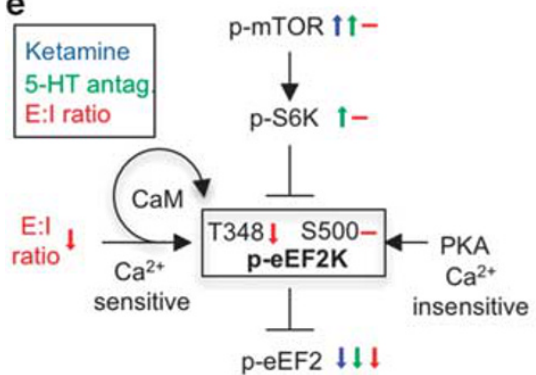

b
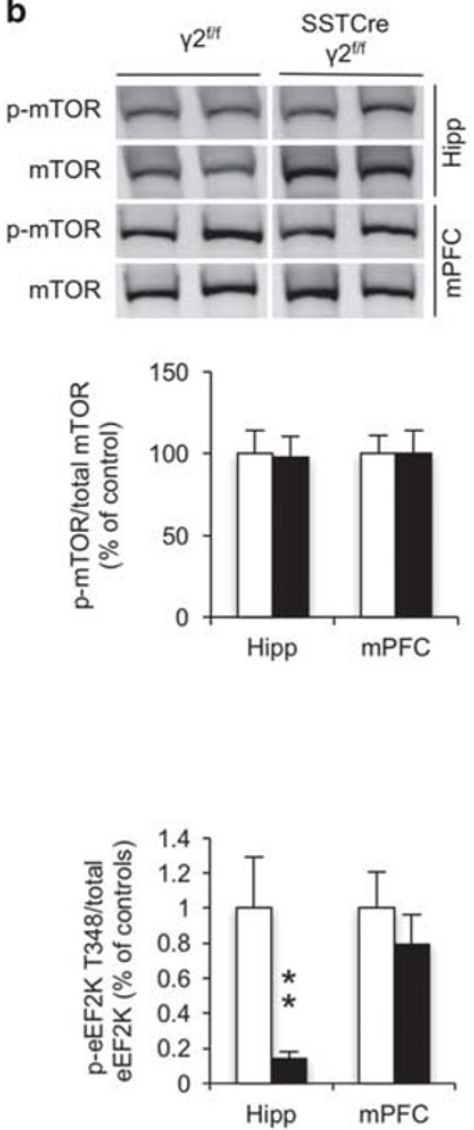

f

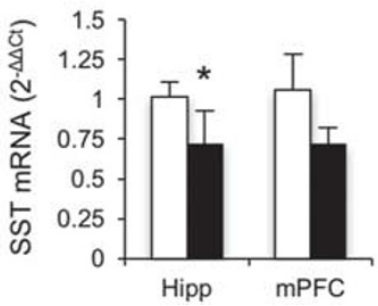

c
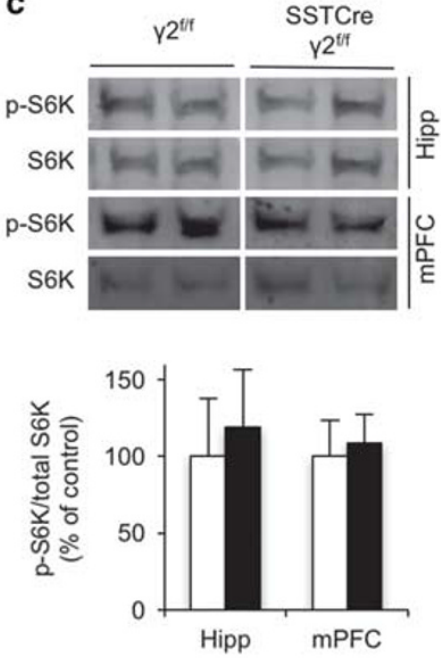

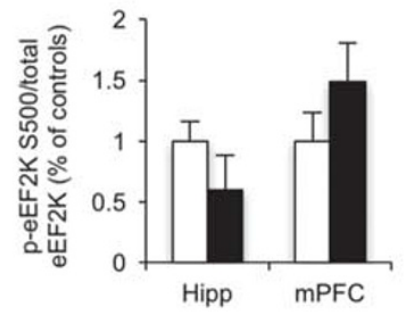

g

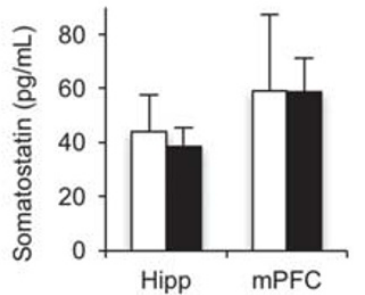

Figure 5. SSTCre: $\gamma 2^{\mathrm{f} / \mathrm{f}}$ mice show biochemical changes indicative of reduced intracellular $\mathrm{Ca}^{2+}$ signaling and increased dendritic translational elongation. (a-c) Representative western blottings and summary statistics for phospho-eukaryotic translational elongation factor 2 ( $p$-eEF2), phospho-mammalian target of rapamycin (p-mTOR) and p-S6K in the hippocampus (Hipp) and medial prefrontal cortex (mPFC) normalized to levels of the respective total proteins in the same samples. Western blottings show a reduction of p-eEF2 ${ }^{T 56} / \mathrm{total}^{\mathrm{eEF} 2}$ in the Hipp and $\mathrm{mPFC}$ of SSTCre: $\gamma 2^{\mathrm{f} / \mathrm{f}} \mathrm{vs} \gamma 2^{\mathrm{f} / \mathrm{f}}$ control mice $\left(P<0.05, n=10\right.$ and 11 , for both hipp and mPFC, $t$-tests) (a). The ratios of p-mTOR ${ }^{\mathrm{S} 2448} / \mathrm{mTOR}^{2}(n=6$ and 6 ; both brain regions) (b) and of $\mathrm{p}-\mathrm{S} 6 \mathrm{~K}^{\mathrm{T} 389} / \mathrm{S} 6 \mathrm{~K}(\mathbf{c})$ were unaffected by genotype ( $P$, NS (non-significant); all four comparisons, $n=6$ and 7 , both brain regions, Mann-Whitney). (d) Representative western blottings and summary statistics of phosphorylation of eEF2 kinase (eEF2K) at T348 and S500, normalized to total eEF2K. A two-way analysis of variance for auto-phosphorylation at T348 revealed significant main effects for genotype $\left(\mathrm{F}_{(1,22)}=10.50, P<0.01\right)$, brain region $\left(\mathrm{F}_{(1,22)}=10.35, P<0.01\right)$ and interaction among the two $\left(\mathrm{F}_{(1,22)}=7.69, P<0.05\right)$. Posthoc tests showed significantly reduced eEF2K $\mathrm{K}^{\mathrm{T} 348}$ auto-phosphorylation in the hippocampus of SSTCre: $\gamma 2^{\mathrm{f} / \mathrm{f}} \mathrm{vs} \gamma 2^{\mathrm{f} / \mathrm{f}}$ controls $(P<0.01, n=5$ and 8$)$ with a tendency in the same direction in $\mathrm{mPFC}\left(P, \mathrm{NS} ; n=5\right.$ and $7, t$-tests). By contrast, no genotype-dependent changes were evident for eEF2 $\mathrm{K}^{5500}$ $(P, \mathrm{NS}$; for both brain regions; $n=5$ and 6 (hipp) and 6 and 8 (mPFC), Mann-Whitney). (e) Schematic of signaling cascades converging on the phospho-state and activity of eEF2K as a target downstream of (i) mTOR- and S6K-mediated inhibitory phosphorylation, (ii) excitationinhibition (E:I) ratio and calmodulin (CaM)-dependent auto-phosphorylation at T348 (activating, black arrow) and (iii) $\mathrm{Ca}^{2+}$-insensitive activating protein kinase A-mediated phosphorylation at S500. Small color-coded arrows illustrate previously reported alterations in phosphostate induced by ketamine (blue ${ }^{29,30}$ ) and 5-HT2C antagonists (green ${ }^{33}$ ) and reported here owing to a reduced synaptic E:I ratio (red, unaltered phospho-states are indicated by a horizontal dash). The unaltered phospho-states of mTOR, S6K and eEF2K ${ }^{5500}$ of SSTCre: $\gamma 2^{\mathrm{f} / \mathrm{f}}$ mice indicate that reduced phosphorylation of eEF2 involves reduced E:I ratio and reduced CaM-mediated auto-phosphorylation of eEF2K at T348. (f) Somatostatin (SST) mRNA levels quantitated by reverse transcriptase-PCR were reduced in hippocampus $\left(2^{-\Delta \Delta t}, P<0.05\right)$ with a trend in the same direction in mPFC ( $P, N S ; n=5$ and 6, Mann-Whitney). (g) SST protein levels quantitated by enzyme-linked immunosorbent assay were not measurably affected by genotype, independent of brain region ( $P, \mathrm{NS} ; n=5$ and 6 (hipp), 5 and 5 (mPFC), Mann-Whitney). Data represent means \pm s.e. ${ }^{*} P<0.05,{ }^{* *} P<0.01$, $t$-tests or Mann-Whitney. 
in slices even in the mutants (Figures $2 \mathrm{~h}$ and I). Interestingly, increased inhibitory synaptic input to CA1 pyramidal cells had no secondary effects on spontaneous EPSCs (Figure $3 \mathrm{~d}$ ). Virtually identical results were observed in $L 2 / 3$ cingulate cortex (Figures 3e, $\mathrm{g}$ and $\mathrm{h}$ ), except that the amplitude of mIPSCs was unaffected by genotype (Figure $3 \mathrm{f}$ ). The passive membrane properties of pyramidal cells assessed by current clamp were unaffected in SSTCre: $2^{\mathrm{f} / \mathrm{f}}$ mice compared with controls, as evidenced by the unaltered number of action potentials elicited across the entire range of currents injected (20-300 pA) (Supplementary Figures S2A-C and E-G), as well as the unaltered resting membrane potentials, independent of brain region (Supplementary Figures S2D and $\mathrm{H}$ ). Thus increasing the excitability of $\mathrm{SST}^{+}$neurons results in a marked and selective increase of GABAergic inhibitory synaptic input to pyramidal target cells.

The behavior of SSTCre: $2^{\mathrm{f} / \mathrm{f}}$ mice mimics the effects of antidepressant drug treatment in anxiety- and depression-related behavioral tests

Before assessing the behavioral consequences of a reduced synaptic E:I ratio in SSTCre: $2^{\mathrm{f} / \mathrm{f}}$ mice, we assessed the emotionrelated behavior of mice that served as controls. The behavior of SSTCre male and female mice analyzed in OFT, FST and EPM was largely indistinguishable from wild-type controls (Supplementary Figures $\mathrm{S} 3 \mathrm{~A}-\mathrm{C}$ ), except for modestly reduced locomotion in an OFT of female mice (Supplementary Figure S3A) and an anxietylike reduction in the time spent in the open arms of an EPM for male mice (Supplementary Figure S3C). These changes occurred in a direction opposite to those found later for SSTCre: $\mathrm{Y} 2^{\mathrm{f} / \mathrm{f}}$ mutant vs $\mathrm{Y}^{\mathrm{f} / \mathrm{f}}$ control mice (see below) and therefore did not interfere with interpretation of behavior of these mutants. SSTCre: $\mathrm{\gamma}^{\mathrm{f} /+}$ mice, which are heterozygous for $\mathrm{\gamma} 2$ in $\mathrm{SST}^{+}$neurons, were indistinguishable from $\mathrm{Y}^{\mathrm{f} / \mathrm{f}}$ pseudo wild-type controls in the same three test paradigms, indicating that inactivation of a single copy of the $\gamma 2$ gene in $\mathrm{SST}^{+}$cells was insufficient to affect behavior and that unspecific Cre activity did not interfere with the behavioral assessment of SSTCre: $\mathrm{\gamma}^{\mathrm{f} / \mathrm{f}}$ mice (Supplementary Figures S3D-F). Hyperexcitability of $\mathrm{SST}^{+}$neurons in SSTCre: $\mathrm{Y}^{\mathrm{f} / \mathrm{f}}$ mice had no overt effects on body weight (Supplementary Figure S4A), fertility or overall health, as evidenced by normal gait, posture and lifespan. However, when examined in a $10 \mathrm{~min}$ OFT, SSTCre: $\mathrm{Y} 2^{\mathrm{f} / \mathrm{f}}$ mice of both sexes showed increased locomotion vs $\mathrm{Y}^{\mathrm{f} / \mathrm{f}}$ controls (Supplementary Figure S1B). This effect was more pronounced in female SSTCre: $2^{\mathrm{f} / \mathrm{f}}$ mice and did not result in altered home cage activity (Supplementary Figure S1B).

To assess the emotional behavioral consequences of $\mathrm{SST}^{+}$cell hyperexcitability, we subjected SSTCre: $\mathrm{Y} 2^{\mathrm{f} / \mathrm{f}}$ mutant mice to a battery of tests sensitive to anxiolytic and antidepressant drug treatment. In the EPM, the mutants showed an increased percentage of open arm entries and an increased percentage of time spent in the open arms compared with $\mathrm{y}^{\mathrm{f} / \mathrm{f}}$ littermate controls, independent of sex (Figure 4a). In light of the increased motor activity described above, it is worth noting that the percentage of open arm entries and the percentage of time spent in open arms are largely independent of locomotion. Moreover, the number of closed arm entries was unaltered by genotype (Figure 4a), indicating that differences on the open arms were due to differences in anxiety and not locomotion. Thus the behavior of SSTCre: $\mathrm{\gamma}^{\mathrm{f} / \mathrm{f}} \mathrm{vs} \mathrm{\gamma} 2^{\mathrm{f} / \mathrm{f}}$ mice in the EPM mimics the effects of classic anxiolytics (that is, benzodiazepines ${ }^{65}$ ), as well as of the rapidly acting antidepressant, ketamine. ${ }^{28}$ In the NSFT, SSTCre $\gamma 2^{\mathrm{f} / \mathrm{f}}$ mice took less time to feed in a novel environment than littermate controls (analysis of variance, $F_{(1,62)}=6.45, P<0.05$ ). Posthoc tests showed that feeding latencies of female SSTCre $\gamma 2^{f / f}$ mice were significantly reduced relative to controls, with a similar but nonsignificant trend also in males (Figure $4 b$ ). Behavioral changes in the NSFT analogous to those of SSTCre: $\gamma 2^{\mathrm{f} / \mathrm{f}}$ mice are observed following chronic but not acute administration of conventional antidepressants, ${ }^{66,67}$ as well as after an acute dose of ketamine..$^{29,32}$ In the FST, SSTCre: $\gamma 2^{\mathrm{f} / \mathrm{f}}$ mice showed a greater latency to assume an immobile position and spent less time in an immobile position than $\mathrm{y}^{\mathrm{f} / \mathrm{f}}$ controls, independent of sex (Figure 4c). Notably, the average swim speed assessed during the first minute of the two sexes combined did not differ between genotypes (Figure 4c). Finally, in the LHT, a male cohort of SSTCre: $\mathrm{Y}^{\mathrm{f} / \mathrm{f}}$ mice showed fewer escape failures compared with $\mathrm{\gamma} 2^{\mathrm{f} / \mathrm{f}}$ littermate controls (Figure 4d). The FST and LHT have strong predictive validity for antidepressant drug activity in patients. ${ }^{68}$ In summary, the behavior of SSTCre: $\mathrm{Y} 2^{\mathrm{f} / \mathrm{f}}$ mice mimics antidepressant drug treatment-induced behavior in four different test paradigms. The behavior of SSTCre: $\gamma 2^{\mathrm{f} / \mathrm{f}}$ mice in a sucrose preference test was unchanged, most likely due to the very high sucrose preference $(\sim 98 \%)$ already in control mice (Supplementary Figure S5A). Learning and memory of SSTCre: $\gamma 2^{\mathrm{f} / \mathrm{f}}$ mice in the Morris water maze was unaffected (Supplementary Figure S5B), suggesting that the behavioral changes of SSTCre: $2^{\mathrm{f} / \mathrm{f}}$ mice were limited to emotional domains and confirming that differences in the FST behavior were not due to altered overall swim speed or motor coordination.

SSTCre: $^{\mathrm{f} / \mathrm{f}}$ mice reproduce biochemical end points of treatment with rapidly acting antidepressants, independent of mTOR activation and altered SST expression

To gain mechanistic insights into the antidepressant-like behavioral phenotype of SSTCre: $2^{\mathrm{f} / \mathrm{f}}$ mice, we examined whether they might show biochemical changes associated with the mechanisms of rapidly acting antidepressants. Interestingly, brain extracts from hippocampus and mPFC of SSTCre: $2^{\mathrm{f} / \mathrm{f}}$ mice showed prominently reduced phosphorylation of eEF2 at T56 (Figure 5a), reminiscent of similar but transient changes in eEF2 ${ }^{\mathrm{T} 56}$ phosphorylation induced in rodents by the experimental antidepressant ketamine ${ }^{29}$ and 5-HT2C antagonists. ${ }^{33}$ Phosphorylation of eEF2 inhibits its function with respect to most mRNA targets. Reduced eEF2 phosphorylation in SSTCre: $2^{\mathrm{f} / \mathrm{f}}$ mice therefore is consistent with increased translation elongation of eEF2-target mRNAs as reported following ketamine treatment. ${ }^{30}$ Importantly, phosphorylation of mTOR and S6K was unchanged in SSTCre: $\mathrm{Y}^{\mathrm{f} / \mathrm{f}}$ mice independent of brain region (Figures $5 \mathrm{~b}$ and $\mathrm{c}$ ), suggesting that in SSTCre: $\mathrm{2}^{\mathrm{f} / \mathrm{f}}$ mice eEF2 activity was controlled by pathways distinct from those activated by rapidly acting antidepressants. Indeed, the key kinase that controls the eEF2 phospho-state and activity, eEF2K, is a target not only of S6K-mediated inhibitory phosphorylation downstream of mTOR but also activated by protein kinase A and CaM-dependent auto-phosphorylation, through nonoverlapping phosphorylation sites. ${ }^{69}$ Interestingly, CaMdependent auto-phosphorylation of eEF2K at T348 was reduced in SSTCre: $\gamma 2^{\mathrm{f} / \mathrm{f}} \mathrm{vS} \gamma 2^{\mathrm{f} / \mathrm{f}}$ mice with a significant effect in hippocampus and a non-significant trend in the same direction also in the mPFC (Figure 2d). By contrast, phosphorylation of eEF2K at S500, which is mediated by protein kinase $\mathrm{A}$ and insensitive to $\mathrm{Ca}^{2+}$ (Ref 70,71$)$ remained unaffected, independent of brain region (Figure 2d). Collectively, the data suggest that the reduced synaptic E:I ratio of principal cells of SSTCre: $2^{\mathrm{f} / \mathrm{f}}$ mice leads to reduced intracellular $\mathrm{Ca}^{2+}$ levels, reduced $\mathrm{Ca}^{2+}$-dependent activating auto-phosphorylation of eEF2K and reduced eEF2K-mediated inhibitory phosphorylation of eEF2 (Figure 2e). Notably, the expression of SST mRNA was reduced in the hippocampus and trended lower in MPFC (Figure 5f), while SST protein levels remained unchanged in SSTCre: $\gamma 2^{\mathrm{f} / \mathrm{f}^{\prime}}$ mice compared with $\mathrm{\gamma} 2^{\mathrm{f} / \mathrm{f}}$ controls independent of the brain regions analyzed (Figure $5 \mathrm{~g}$ ). The data suggest that the antidepressant-like brain state of SSTCre: $2^{\mathrm{f} / \mathrm{f}}$ mice that is caused by increased excitability of $\mathrm{SST}^{+}$interneurons did not involve increased SST expression (see Discussion). 


\section{DISCUSSION}

We here provide direct evidence that reducing the synaptic E:I ratio of principal neurons by functional potentiation of a GABAergic inhibitory synaptic input to principal cells is sufficient to induce a sustained antidepressant-like phenotype that includes both behavioral and biochemical end points of antidepressant drug treatment. Our findings are consistent with the GABAergic deficit hypothesis of MDD, which posits that defects in GABAergic transmission may be causal for depressive disorders and that antidepressant therapies involve enhancement of GABAergic synaptic transmission. ${ }^{22}$

Intracerebroventricular infusion of an SST peptide has anxiolytic- and antidepressant-like behavioral consequences, ${ }^{72}$ raising the question of whether hyperexcitability of $\mathrm{SST}^{+}$neurons leads to increased expression and release of SST that might contribute to the behavioral phenotype of SSTCre: $\gamma 2^{\mathrm{f} / \mathrm{f}}$ mice. However, SST mRNA was reduced rather than increased and we found no measurable change in the expression of $\mathrm{SST}^{+}$protein in the brain of SSTCre: $\mathrm{F}^{\mathrm{f} / \mathrm{f}}$ mice (Figures $5 \mathrm{f}$ and $\mathrm{g}$ ). Furthermore, treatment of cultured neurons with purified SST peptide leads to profound reductions in the density and function of excitatory synapses without changing the function of inhibitory synapses, ${ }^{73}$ which is opposite to the synaptic alterations observed in SSTCre: $\gamma 2^{\mathrm{f} / \mathrm{f}}$ mice. Acute silencing of frontal cortex $\mathrm{SST}^{+}$interneurons results in an anxious-depressive-like phenotype in mice, while chronic silencing or ablation has the opposite effect. ${ }^{74}$ Although these experiments point to a central role of $\mathrm{SST}^{+}$neurons in emotion regulation, they were not designed to discriminate between loss of GABAergic inhibition and loss of SST function. Thus the collective evidence is consistent with the antidepressant phenotype of SSTCre: $2^{\mathrm{f} / \mathrm{f}}$ mice owing to increased inhibitory synaptic input to principal cells.

$\mathrm{SST}^{+}$neurons are known to target preferentially the dendrites of principal neurons. However, they also provide inhibitory input to parvalbumin-positive $\left(\mathrm{PV}^{+}\right)$interneurons. In addition to innervating each other, $\mathrm{PV}^{+}$interneurons synapse preferentially onto the perisomatic region and axon initial segment of pyramidal cells, thereby controlling their spike output. ${ }^{75,76}$ Thus increased inhibition of $\mathrm{PV}^{+}$cells by hyperactive SST neurons of SSTCre: $\gamma 2^{\mathrm{f} / \mathrm{f}}$ mice might result in disinhibition of pyramidal cells. The increased mIPSC amplitude observed in CA1 pyramidal cells of SSTCre: $2^{\mathrm{f} / \mathrm{f}}$ might reflect chronically reduced input at a subset of synaptic inputs originating from $\mathrm{PV}^{+}$cells, as sustained activation of GABAergic synapses is known to result in dispersal of $G_{A B A} R s$ from synapses. ${ }^{77}$ However, the increased sIPSC frequency of SSTCre: $2^{f / f}$ pyramidal cells is inconsistent with reduced overall inhibition of pyramidal cells by $\mathrm{PV}^{+}$cells. Moreover, preliminary

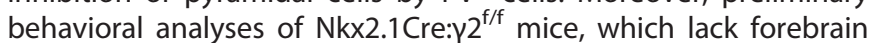
$\mathrm{GABA}_{\mathrm{A}} \mathrm{Rs}$ in both $\mathrm{PV}^{+}$and $\mathrm{SST}^{+}$interneurons, show an antidepressive-like phenotype comparable to that of SSTCre: $2^{\mathrm{f} / \mathrm{f}}$ mice, indicating that disinhibition of $\mathrm{PV}^{+}$cells does not contribute materially to the behavioral phenotype of SSTCre: $2^{\mathrm{f} / \mathrm{f}}$ mice (Fuchs and Luscher, unpublished). The collective evidence suggests that the behavioral phenotype of SSTCre: $2^{\mathrm{f} / \mathrm{f}}$ mice reflects increased GABAergic inhibition of pyramidal cells by disinhibited $\mathrm{SST}^{+}$cells.

The behavioral changes of SSTCre: $2^{\mathrm{f} / \mathrm{f}}$ mice were paralleled by reduced phosphorylation of eEF2, reminiscent of biochemical end points of treatments with antidepressant doses of ketamine $29,30,36$ and $5-\mathrm{HT} 2 \mathrm{C}$ receptor antagonists. ${ }^{33}$ In contrast to drug-induced reductions in eEF2 phosphorylation, which involve transient activation of mTOR ${ }^{29,33,78-80}$ (however, see Autry et al. $^{30}$ and Zanos et al. $^{32}$ ), this pathway was unaffected in SSTCre: $2^{\mathrm{f} / \mathrm{f}}$ mice, as evidenced by unaltered mTOR and S6K phosphorylation. Instead, reduced phosphorylation of eEF2 was likely a consequence of the reduced synaptic E:I ratio of principal cells (Figure 3), correspondingly reduced NMDA receptor-mediated $\mathrm{Ca}^{2+}$ influx ${ }^{42}$ and reduced CaM-dependent auto-phosphorylation of eEF2K (Figure $5 \mathrm{~d}$ ), which has eEF2 as a single known target $^{81}$ (Figure 5e). CaM-dependent auto-phosphoryation of eEF2 $\mathrm{K}^{\mathrm{T} 348}$ can largely account for the reduced activity of this enzyme that is evident based on reduced phosphorylation of eEF2 (Figure 5a). Curiously, the change in eEF2K ${ }^{T 348}$ phosphorylation evident in the hippocampus was not significant in $\mathrm{mPFC}$, perhaps owing to the higher interneuron content in that brain region. The $\mathrm{E}: \mathrm{l}$ ratio change in $\mathrm{SST}^{+}$ interneurons of SSTCre: $\mathrm{Y}^{\mathrm{f} / \mathrm{f}}$ mice is inverse to that in principal cells (Figures 2 and 3), suggesting that opposite E:I ratiodependent biochemical changes in these two cell types could hamper the detection of such cell-type-specific changes in brain extracts.

In vivo, $\mathrm{SST}^{+}$interneurons often form inhibitory synapses onto dendritic spines of pyramidal cells. Moreover, they are subject to feedback excitation from local pyramidal cells, indicating that they are tailored to limit the gain in network activity. ${ }^{43}$ Consistent with such a role, $\mathrm{SST}^{+}$interneurons have been shown to control compartmentalized NMDA receptor-mediated $\mathrm{Ca}^{2+}$ entry into individual spines, which is thought to control dendritic spike generation and the firing rate of glutamatergic cells. ${ }^{42,43}$ Pharmacological manipulation of the excitability of cultured neurons ${ }^{34}$ and the data presented here indicate that this same mechanism regulates local dendritic eEF2K activity and eEF2-dependent mRNA translation, a process that has also recently been implicated in antidepressant mechanisms of ketamine. $^{36}$

\section{CONCLUSION}

Collectively, the data indicate that chronically increasing the inhibitory synaptic input from $\mathrm{SST}^{+}$interneurons to dendrites of principal cells results in enduring behavioral alterations and biochemical changes that mimic the potent but transient effects of rapidly acting experimental antidepressants, such as ketamine. At the cellular level, this mechanism involves a chronically increased excitability of $\mathrm{SST}^{+}$neurons, a correspondingly reduced $\mathrm{E}:$ I ratio of synaptic inputs from $\mathrm{SST}^{+}$neurons to glutamatergic neurons, reduced CaM-mediated activation of eEF2K and reduced eEF2K-mediated phosphorylation of eEF2. eEF2K and eEF2 are established effectors of rapidly acting antidepressants and known to regulate dendritic mRNA translation. Identification of the eEF2target mRNAs that are subject to chronically altered translation in SSTCre: $^{\mathrm{f} / \mathrm{f}}$ mice should facilitate the identification of novel targets for chronically effective antidepressant therapies.

\section{CONFLICT OF INTEREST}

The authors declare no conflict of interest.

\section{ACKNOWLEDGMENTS}

We thank Yao Guo for technical assistance and Ting-Yu Kua for help with genotyping of mice. BL thanks JM Fritsch and P Panzanelli for their hosting of his sabbatical and providing excellent training in immunohistochemistry that was instrumental for this work. This publication was made possible by grants MH097247 and MH099851 from the National Institute of Mental Health (NIMH) to BL and NS073574 from the National Institute of Neurological Disorders and Stroke (NINDS) to JM. Its contents are solely the responsibility of the authors and do not necessarily represent the views of the NIMH or the NINDS.

\section{REFERENCES}

1 Kessler RC, Berglund P, Demler O, Jin R, Koretz D, Merikangas KR et al. The epidemiology of major depressive disorder: results from the National Comorbidity Survey Replication (NCS-R). JAMA 2003; 289: 3095-3105.

2 Choudary PV, Molnar M, Evans SJ, Tomita H, Li JZ, Vawter MP et al. Altered cortical glutamatergic and GABAergic signal transmission with glial involvement in depression. Proc Natl Acad Sci USA 2005; 102: 15653-15658. 
3 Miguel-Hidalgo JJ, Waltzer R, Whittom AA, Austin MC, Rajkowska G, Stockmeier CA. Glial and glutamatergic markers in depression, alcoholism, and their comorbidity. J Affect Disord 2010; 127: 230-240.

4 Hashimoto K, Malchow B, Falkai P, Schmitt A. Glutamate modulators as potential therapeutic drugs in schizophrenia and affective disorders. Eur Arch Psychiatry Clin Neurosci 2013; 263: 367-377.

5 Sanacora G, Mason GF, Rothman DL, Behar KL, Hyder F, Petroff OA et al. Reduced cortical gamma-aminobutyric acid levels in depressed patients determined by proton magnetic resonance spectroscopy. Arch Gen Psychiatry 1999; 56: 1043-1047.

6 Hasler G, van der Veen JW, Tumonis T, Meyers N, Shen J, Drevets WC. Reduced prefrontal glutamate/glutamine and gamma-aminobutyric acid levels in major depression determined using proton magnetic resonance spectroscopy. Arch Gen Psychiatry 2007; 64: 193-200.

7 Gabbay V, Mao X, Klein RG, Ely BA, Babb JS, Panzer AM et al. Anterior cingulate cortex gamma-aminobutyric acid in depressed adolescents: relationship to anhedonia. Arch Gen Psychiatry 2012; 69: 139-149.

8 Bhagwagar Z, Wylezinska M, Jezzard P, Evans J, Ashworth F, Sule A et al. Reduction in occipital cortex gamma-aminobutyric acid concentrations in medication-free recovered unipolar depressed and bipolar subjects. Biol Psychiatry 2007; 61: 806-812.

9 Price RB, Shungu DC, Mao X, Nestadt P, Kelly C, Collins KA et al. Amino acid neurotransmitters assessed by proton magnetic resonance spectroscopy: relationship to treatment resistance in major depressive disorder. Biol Psychiatry 2009; 65: 792-800.

10 Croarkin PE, Levinson AJ, Daskalakis ZJ. Evidence for GABAergic inhibitory deficits in major depressive disorder. Neurosci Biobehav Rev 2011; 35: 818-825.

11 Klumpers UM, Veltman DJ, Drent ML, Boellaard R, Comans EF, Meynen G et al. Reduced parahippocampal and lateral temporal GABAA-[11C]flumazenil binding in major depression: preliminary results. Eur J Nucl Med Mol Imaging 2010; 37: 565-574.

12 Karolewicz B, Maciag D, O'Dwyer G, Stockmeier CA, Feyissa AM, Rajkowska G. Reduced level of glutamic acid decarboxylase- $67 \mathrm{kDa}$ in the prefrontal cortex in major depression. Int J Neuropsychopharmacol 2010; 13: 411-420.

13 Guilloux JP, Douillard-Guilloux G, Kota R, Wang X, Gardier AM, Martinowich K et al. Molecular evidence for BDNF- and GABA-related dysfunctions in the amygdala of female subjects with major depression. Mol Psychiatry 2012; 17: 1130-1142.

14 Sibille E, Morris HM, Kota RS, Lewis DA. GABA-related transcripts in the dorsolateral prefrontal cortex in mood disorders. Int J Neuropsychopharmacol 2011; 14: 721-734.

15 Rajkowska G, O'Dwyer G, Teleki Z, Stockmeier CA, Miguel-Hidalgo JJ. GABAergic neurons immunoreactive for calcium binding proteins are reduced in the prefrontal cortex in major depression. Neuropsychopharmacology 2007; 32: 471-482.

16 Maciag D, Hughes J, O'Dwyer G, Pride Y, Stockmeier CA, Sanacora G et al. Reduced density of calbindin immunoreactive GABAergic neurons in the occipital cortex in major depression: relevance to neuroimaging studies. Biol Psychiatry 2010; 67: 465-470.

17 Hewitt SA, Wamsteeker J, Kurz EU, Bains JS. Altered chloride homeostasis removes synaptic inhibitory constraint of the stress axis. Nat Neurosci 2009; 12: 438-443.

18 MacKenzie G, Maguire J. Chronic stress shifts the GABA reversal potential in the hippocampus and increases seizure susceptibility. Epilepsy Res 2015; 109: 13-27.

19 Liu ZP, Song C, Wang M, He Y, Xu XB, Pan HQ et al. Chronic stress impairs GABAergic control of amygdala through suppressing the tonic GABAA receptor currents. Mol Brain 2014; 7: 32.

20 Lin LC, Sibille E. Somatostatin, neuronal vulnerability and behavioral emotionality. Mol Psychiatry 2015; 20: 377-387.

21 Maguire J. Stress-induced plasticity of GABAergic inhibition. Front Cell Neurosci 2014; 8: 157.

22 Luscher B, Fuchs T. GABAergic control of depression-related brain states. Adv Pharmacol 2015; 73: 97-144.

23 Bains JS, Wamsteeker Cusulin JI, Inoue W. Stress-related synaptic plasticity in the hypothalamus. Nat Rev Neurosci 2015; 16: 377-388.

24 Sanacora G, Mason GF, Rothman DL, Hyder F, Ciarcia JJ, Ostroff RB et al. Increased cortical GABA concentrations in depressed patients receiving ECT. Am J Psychiatry 2003; 160: 577-579.

25 Sanacora G, Mason GF, Rothman DL, Krystal JH. Increased occipital cortex GABA concentrations in depressed patients after therapy with selective serotonin reuptake inhibitors. Am J Psychiatry 2002; 159: 663-665.

26 Hasler G, Neumeister A, van der Veen JW, Tumonis T, Bain EE, Shen J et al. Normal prefrontal gamma-aminobutyric acid levels in remitted depressed subjects determined by proton magnetic resonance spectroscopy. Biol Psychiatry 2005; 58: 969-973.

27 Shen Q, Lal R, Luellen BA, Earnheart JC, Andrews AM, Luscher B. gammaAminobutyric acid-type A receptor deficits cause hypothalamic-pituitary-adrenal axis hyperactivity and antidepressant drug sensitivity reminiscent of melancholic forms of depression. Biol Psychiatry 2010; 68: 512-520.

28 Ren Z, Pribiag H, Jefferson SJ, Shorey M, Fuchs T, Stellwagen D et al. Bidirectional homeostatic regulation of a depression-related brain state by gammaaminobutyric acidergic deficits and ketamine treatment.. Biol Psychiatry 2016; 80: 457-468.

29 Li N, Lee B, Liu RJ, Banasr M, Dwyer JM, Iwata M et al. mTOR-dependent synapse formation underlies the rapid antidepressant effects of NMDA antagonists. Science 2010; 329: 959-964.

30 Autry $\mathrm{AE}$, Adachi M, Nosyreva E, Na ES, Los MF, Cheng PF et al. NMDA receptor blockade at rest triggers rapid behavioural antidepressant responses. Nature 2011; 475: 91-95.

31 Duman RS, Li N, Liu RJ, Duric V, Aghajanian G. Signaling pathways underlying the rapid antidepressant actions of ketamine. Neuropharmacology 2012; 62: 35-41.

32 Zanos P, Moaddel R, Morris PJ, Georgiou P, Fischell J, Elmer Gl et al. NMDAR inhibition-independent antidepressant actions of ketamine metabolites. Nature 2016; 533: 481-486.

33 Opal MD, Klenotich SC, Morais M, Bessa J, Winkle J, Doukas D et al. Serotonin 2C receptor antagonists induce fast-onset antidepressant effects. Mol Psychiatry 2014; 19: 1106-1114.

34 Sutton MA, Taylor AM, Ito HT, Pham A, Schuman EM. Postsynaptic decoding of neural activity: eEF2 as a biochemical sensor coupling miniature synaptic transmission to local protein synthesis. Neuron 2007; 55: 648-661.

35 Verpelli C, Piccoli G, Zibetti C, Zanchi A, Gardoni F, Huang K et al. Synaptic activity controls dendritic spine morphology by modulating eEF2-dependent BDNF synthesis. J Neurosci 2010; 30: 5830-5842.

36 Monteggia LM, Gideons E, Kavalali ET. The role of eukaryotic elongation factor 2 kinase in rapid antidepressant action of ketamine. Biol Psychiatry 2013; 73: 1199-1203.

37 Tripp A, Kota RS, Lewis DA, Sibille E. Reduced somatostatin in subgenual anterior cingulate cortex in major depression. Neurobiol Dis 2011; 42: 116-124.

38 Tripp A, Oh H, Guilloux JP, Martinowich K, Lewis DA, Sibille E. Brain-derived neurotrophic factor signaling and subgenual anterior cingulate cortex dysfunction in major depressive disorder. Am J Psychiatry 2012; 169: 1194-1202.

39 Rudy B, Fishell G, Lee S, Hjerling-Leffler J. Three groups of interneurons account for nearly $100 \%$ of neocortical GABAergic neurons. Dev Neurobiol 2011; 71: 45-61.

40 Silberberg G, Markram H. Disynaptic inhibition between neocortical pyramidal cells mediated by Martinotti cells. Neuron 2007; 53: 735-746.

41 Viollet C, Lepousez G, Loudes C, Videau C, Simon A, Epelbaum J. Somatostatinergic systems in brain: networks and functions. Mol Cell Endocrinol 2008; 286: 75-87.

42 Chiu CQ, Lur G, Morse TM, Carnevale NT, Ellis-Davies GC, Higley MJ. Compartmentalization of GABAergic inhibition by dendritic spines. Science 2013; 340: 759-762.

43 Higley MJ. Localized GABAergic inhibition of dendritic $\mathrm{Ca}(2+)$ signalling. Nat Rev Neurosci 2014; 15: 567-572.

44 Maccaferri G, McBain CJ. Passive propagation of LTD to stratum oriens-alveus inhibitory neurons modulates the temporoammonic input to the hippocampal CA1 region. Neuron 1995; 15: 137-145.

45 Leao RN, Mikulovic S, Leao KE, Munguba H, Gezelius H, Enjin A et al. OLM interneurons differentially modulate CA3 and entorhinal inputs to hippocampal CA1 neurons. Nat Neurosci 2012; 15: 1524-1530.

46 Thompson SM, Kallarackal AJ, Kvarta MD, Van Dyke AM, LeGates TA, Cai X. An excitatory synapse hypothesis of depression. Trends Neurosci 2015; 38: 279-294.

47 Fanselow EE, Richardson KA, Connors BW. Selective, state-dependent activation of somatostatin-expressing inhibitory interneurons in mouse neocortex. I Neurophysiol 2008; 100: 2640-2652.

48 Buzsaki G, Csicsvari J, Dragoi G, Harris K, Henze D, Hirase H. Homeostatic maintenance of neuronal excitability by burst discharges in vivo. Cereb Cortex 2002; 12: 893-899.

49 Klausberger T, Magill PJ, Marton LF, Roberts JD, Cobden PM, Buzsaki G et al. Brain-state- and cell-type-specific firing of hippocampal interneurons in vivo. Nature 2003; 421: 844-848.

50 Muller C, Remy S. Dendritic inhibition mediated by O-LM and bistratified interneurons in the hippocampus. Front Synaptic Neurosci 2014; 6: 23.

51 McNaughton N, Kocsis B, Hajos M. Elicited hippocampal theta rhythm: a screen for anxiolytic and procognitive drugs through changes in hippocampal function? Behav Pharmacol 2007; 18: 329-346.

52 Essrich C, Lorez M, Benson J, Fritschy J-M, Luscher B. Postsynaptic clustering of major $G A B A(A)$ receptor subtypes requires the gamma2 subunit and gephyrin. Nat Neurosci 1998; 1: 563-571.

53 Schweizer C, Balsiger S, Bluethmann H, Mansuy IM, Fritschy JM, Mohler $\mathrm{H}$ et al. The gamma 2 subunit of $\operatorname{GABA}(\mathrm{A})$ receptors is required for maintenance of receptors at mature synapses. Mol Cell Neurosci 2003; 24: 442-450. 
54 Li RW, Yu W, Christie S, Miralles CP, Bai J, Loturco JJ et al. Disruption of postsynaptic GABA receptor clusters leads to decreased GABAergic innervation of pyramidal neurons. J Neurochem 2005; 95: 756-770.

55 Ren Z, Sahir N, Murakami S, Luellen BA, Earnheart JC, Lal R et al. Defects in dendrite and spine maturation and synaptogenesis associated with an anxiousdepressive-like phenotype of GABAA receptor-deficient mice. Neuropharmacology 2015; 88: 171-179.

56 Srinivas S, Watanabe T, Lin CS, William CM, Tanabe Y, Jessell TM et al. Cre reporter strains produced by targeted insertion of EYFP and ECFP into the ROSA26 locus. BMC Dev Biol 2001; 1: 4.

57 Shen Q, Fuchs T, Sahir N, Luscher B. GABAergic control of critical developmental periods for anxiety- and depression-related behavior in mice. PLoS One 2012; 7: e47441.

58 Lee V, Maguire J. Impact of inhibitory constraint of interneurons on neuronal excitability. J Neurophysiol 2013; 110: 2520-2535.

59 Lister RG. The use of a plus-maze to measure anxiety in the mouse. Psychopharmacology 1987; 92: 180-185.

60 Santarelli L, Saxe M, Gross C, Surget A, Battaglia F, Dulawa S et al. Requirement of hippocampal neurogenesis for the behavioral effects of antidepressants. Science 2003; 301: 805-809.

61 Lucki I. The forced swimming test as a model for core and component behavioral effects of antidepressant drugs. Behav Pharmacol 1997; 8: 523-532.

62 Newton SS, Thome J, Wallace TL, Shirayama Y, Schlesinger L, Sakai N et al. Inhibition of CAMP response element-binding protein or dynorphin in the nucleus accumbens produces an antidepressant-like effect. J Neurosci 2002; 22: 10883-10890.

63 Gunther U, Benson J, Benke D, Fritschy JM, Reyes G, Knoflach F et al. Benzodiazepine-insensitive mice generated by targeted disruption of the gamma 2 subunit gene of gamma-aminobutyric acid type A receptors. Proc Natl Acad Sci USA 1995; 92: 7749-7753.

64 Taniguchi $\mathrm{H}$, He M, Wu P, Kim S, Paik R, Sugino $\mathrm{K}$ et al. A resource of Cre driver lines for genetic targeting of GABAergic neurons in cerebral cortex. Neuron 2011; 71: 995-1013.

65 Low K, Crestani F, Keist R, Benke D, Brunig I, Benson JA et al. Molecular and neuronal substrate for the selective attenuation of anxiety. Science 2000; 290: $131-134$.

66 Bodnoff SR, Suranyi-Cadotte B, Aitken DH, Quirion R, Meaney MJ. The effects of chronic antidepressant treatment in an animal model of anxiety. Psychopharmacology 1988; 95: 298-302.

67 Earnheart JC, Schweizer C, Crestani F, Iwasato T, Itohara S, Mohler H et al. GABAergic control of adult hippocampal neurogenesis in relation to behavior indicative of trait anxiety and depression states. J Neurosci 2007; 27: 3845-3854.

68 Nestler EJ, Gould E, Manji H, Buncan M, Duman RS, Greshenfeld HK et al. Preclinical models: status of basic research in depression. Biol Psychiatry 2002; 52: 503-528

69 Proud CG. Signalling to translation: how signal transduction pathways control the protein synthetic machinery. Biochem J 2007; 403: 217-234.
70 Redpath NT, Proud CG. Cyclic AMP-dependent protein kinase phosphorylates rabbit reticulocyte elongation factor-2 kinase and induces calcium-independent activity. Biochem J 1993; 293(Pt 1): 31-34.

71 Diggle TA, Subkhankulova $T$, Lilley $K S$, Shikotra $N$, Willis $A E$, Redpath NT. Phosphorylation of elongation factor-2 kinase on serine 499 by cAMP-dependent protein kinase induces Ca2+/calmodulin-independent activity. Biochem J 2001; 353(Pt 3): 621-626.

72 Engin E, Stellbrink J, Treit D, Dickson CT. Anxiolytic and antidepressant effects of intracerebroventricularly administered somatostatin: behavioral and neurophysiological evidence. Neuroscience 2008; 157: 666-676.

$73 \mathrm{Hou} \mathrm{ZH}, \mathrm{Yu}$ X. Activity-regulated somatostatin expression reduces dendritic spine density and lowers excitatory synaptic transmission via postsynaptic somatostatin receptor 4. J Biol Chem 2013; 288: 2501-2509.

74 Soumier A, Sibille E. Opposing effects of acute versus chronic blockade of frontal cortex somatostatin-positive inhibitory neurons on behavioral emotionality in mice. Neuropsychopharmacology 2014; 39: 2252-2262.

75 Pfeffer CK, Xue M, He M, Huang ZJ, Scanziani M. Inhibition of inhibition in visual cortex: the logic of connections between molecularly distinct interneurons. Nat Neurosci 2013; 16: 1068-1076.

76 Somogyi P, Klausberger T. Defined types of cortical interneurone structure space and spike timing in the hippocampus. J Physiol 2005; 562(Pt 1): 9-26.

77 Gouzer G, Specht CG, Allain L, Shinoe T, Triller A. Benzodiazepine-dependent stabilization of $\operatorname{GABA}(\mathrm{A})$ receptors at synapses. Mol Cell Neurosci 2014; 63: 101-113.

78 Harraz MM, Tyagi R, Cortes P, Snyder SH. Antidepressant action of ketamine via mTOR is mediated by inhibition of nitrergic Rheb degradation. Mol Psychiatry 2016; 21: 313-319.

79 Tang J, Xue W, Xia B, Ren L, Tao W, Chen C et al. Involvement of normalized NMDA receptor and mTOR-related signaling in rapid antidepressant effects of Yueju and ketamine on chronically stressed mice. Sci Rep 2015; 5: 13573.

80 Zhou W, Wang N, Yang C, Li XM, Zhou ZQ, Yang JJ. Ketamine-induced antidepressant effects are associated with AMPA receptors-mediated upregulation of mTOR and BDNF in rat hippocampus and prefrontal cortex. Eur Psychiatry 2013; 29: 419-423.

81 Heise C, Gardoni F, Culotta L, di Luca M, Verpelli C, Sala C. Elongation factor-2 phosphorylation in dendrites and the regulation of dendritic mRNA translation in neurons. Front Cell Neurosci 2014; 8: 35 .

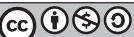

This work is licensed under a Creative Commons AttributionNonCommercial-ShareAlike 4.0 International License. The images or other third party material in this article are included in the article's Creative Commons license, unless indicated otherwise in the credit line; if the material is not included under the Creative Commons license, users will need to obtain permission from the license holder to reproduce the material. To view a copy of this license, visit http:// creativecommons.org/licenses/by-nc-sa/4.0/

(c) The Author(s) 2017

Supplementary Information accompanies the paper on the Molecular Psychiatry website (http://www.nature.com/mp) 